\title{
Specific Impairment of "What-Where-When" Episodic-Like Memory in Experimental Models of Temporal Lobe Epilepsy
}

\author{
Marion Inostroza, ${ }^{1,2 \star}$ Jorge R. Brotons-Mas, ${ }^{1 \star}$ François Laurent, ${ }^{1}$ Elena Cid, ${ }^{1}$ and Liset Menendez de la Prida ${ }^{1}$ \\ ${ }^{1}$ Instituto Cajal, Consejo Superior de Investigaciones Científicas, 28012 Madrid, Spain, and ${ }^{2}$ Departamento de Psicología, Universidad de Chile, Santiago \\ 1058, Chile
}

\begin{abstract}
Episodic memory deficit is a common cognitive disorder in human temporal lobe epilepsy (TLE). However, no animal model of TLE has been shown to specifically replicate this cognitive dysfunction, which has limited its translational appeal. Here, using a task that tests for nonverbal correlates of episodic-like memory in rats, we show that kainate-treated TLE rats exhibit a selective impairment of the "what-where-when" memory while preserving other forms of hippocampal-dependent memories. Assisted by multisite silicon probes, we recorded from the dorsal hippocampus of behaving animals to control for seizure-related factors and to look for electrophysiological signatures of cognitive impairment. Analyses of hippocampal local field potentials showed that both the power of theta rhythm and its coordination across CA1 and the DG-measured as theta coherence and phase locking-were selectively disrupted. This disruption represented a basal condition of the chronic epileptic hippocampus that was linked to different features of memory impairment. Theta power was more correlated with the spatial than with the temporal component of the task, while measures of theta coordination correlated with the temporal component. We conclude that episodic-like memory, as tested in the what-where-when task, is specifically affected in experimental TLE and that the impairment of hippocampal theta activity might be central to this dysfunction.
\end{abstract}

\section{Introduction}

Episodic memory is defined as the ability to consciously recall previous experiences that held temporally dated information and spatiotemporal relations (Tulving and Markowitsch, 1998; Davachi, 2006). Deficits of episodic memory are present during aging and in many neurological conditions including Alzheimer's disease and certain forms of epilepsy (Helmstaedter 2002; Maguire and Frith, 2003; Addis et al., 2007). However, the basic mechanisms both in health and disease are unknown.

Although episodic memory is closely associated with language and consciousness, paradigms have been devised to test for episodic-like memory in animals (Clayton and Dickinson, 1998). Thus, the specific attributes of an episode are separated into the "what" happens "where," with contextual information (temporal "when" or circumstantial "which") being implicitly considered (Eacott and Norman, 2004). The ability to simultaneously integrate these features of unique experiences is considered a valid

Received March 4, 2013; revised Sept. 3, 2013; accepted Sept. 26, 2013.

Author contributions: M.I., J.R.B.-M., and L.M.d.I.P. designed research; M.I., J.R.B.-M., E.C., and L.M.d.I.P. performed research; M.I., J.R.B.-M., F.L., and L.M.d.I.P. analyzed data; L.M.d.I.P. wrote the paper.

This work was supported by grants from the Spanish Ministerio de Ciencia e Innovación (BFU2009-07989), the Fundación Alicia Koplowitz, the ERA-Net-Neuron project EPINet (EUI2009-04093), and by the European Commission under FP7 (MemStick Grant Agreement No. 201600). E.C. is a JAE-Doc fellow from the Consejo Superior de Investigaciones Científicas JAEProgram cofunded by the European Social Fund. We are grateful to Richard Miles, John Gigg, and Jan Born for helpful comments and discussion.

${ }^{*}$ M.I. and J.R.B.-M. contributed equally to this study.

Correspondence should be addressed to Liset Menendez de la Prida, Instituto Cajal CSIC, Avenida Doctor Arce, 37, 28012 Madrid, Spain. E-mail: Imprida@cajal.csic.es.

M. Inostroza's present address: Institute of Medical Psychology and Behavioral Neurobiology, Eberhard Karls University of Tübingen, 72076 Tübingen, Germany.

DOI:10.1523/JNEUROSCI.0957-13.2013

Copyright $\odot 2013$ the authors $\quad 0270-6474 / 13 / 3317749-14 \$ 15.00 / 0$ experimental definition of this memory type (Griffiths et al., 1999; Pause et al., 2010).

Using the spontaneous preference of rodents for novelty, singletrial object recognition tasks have been refined to test for episodiclike memory processes (Ennaceur and Delacour, 1988; Aggleton and Pearce, 2001; Fortin et al., 2002; Eacott and Norman, 2004; Langston and Wood, 2010) and, specifically, for the what, where, and when components of unique experiences (Dere et al., 2005; Kart-Teke et al., 2006; DeVito and Eichenbaum, 2010). A similar version of the "what-where-when" task applied to humans confirms that it tests for nonverbal behavioral correlates of episodic memory (Pause et al., 2010). Thus, the what-where-when task, by involving long delays (up to $100 \mathrm{~min}$ ) and by combining both spatial and temporal aspects, allows for evaluation of episodic-like memory in animals.

There is evidence that different neuronal inputs, carrying information from upstream cortical layers, converge on the hippocampus to create unique contextual meanings (Morris, 2001; Davachi, 2006; Witter et al., 2000; Eichenbaum et al., 2007). Therefore, the role of the hippocampus in episodic memory should depend on its capacity to bind these attributes of unique experiences into a spatiotemporal representation (MacDonald et al., 2011; Naya and Suzuki, 2011). However, investigation of neuronal processes underlying memory for single events remains a methodological challenge (MacDonald et al., 2011; Tort et al., 2011). The possibility to test for the snapshot nature of whatwhere-when memory provides unique opportunities to unravel the underlying mechanisms in animal models of disease (LenckSantini et al., 2005; Knierim et al., 2006; Good et al., 2007; Chang and Huerta, 2012; Davis et al., 2013).

Here we used the what-where-when object recognition task (Kart-Teke et al., 2006) to probe episodic-like memory abilities in 
a rat model of temporal lobe epilepsy (TLE). Previously, we confirmed that these animals successfully learn and remember a hippocampal-dependent spatial memory task in the Morris water maze (Inostroza et al., 2011). We used these chronic TLE rats to test for the specific disturbance of the integrated what-wherewhen memory, as well as for memory of individual components of episodic-like memory. We obtained multisite recordings of hippocampal local field potentials (LFPs) to relate changes of neuronal dynamics with specific disruption of different cognitive aspects of episodic-like memory function.

\section{Materials and Methods}

A major concern in looking at the neuronal basis of cognitive deficits in TLE is to separate effects of seizures, interictal activity, and brain lesions (Aldenkamp, 1997; Holmes and Lenck-Santini, 2006). We have shown that Wistar rats with chronic epilepsy induced by low doses of kainate exhibit major neuropathological TLE features in an otherwise relatively intact brain (Inostroza et al., 2011). These animals show cell loss confined to the hippocampus and not affecting the amygdala and other structures. They have normal anxiety levels and hypothalamic-pituitary-adrenal axis functioning, while suffering seizures of similar features to other lesion models (Inostroza et al., 2011, 2012). Also, in contrast to other TLE models, these rats successfully learn the Morris water maze (Inostroza et al., 2011) and the hippocampal-dependent version of an object recognition task (Suárez et al., 2012). Hence, we chose to use this model to look at specific disturbances of episodic-like memory using the what-wherewhen task (Kart-Teke et al., 2006).

Animals. Adult male Wistar rats $(180-200 \mathrm{~g})$ were housed individually under controlled conditions $\left(\sim 22-24^{\circ} \mathrm{C}, 12 \mathrm{~h}\right.$ light/dark cycle) and fed ad libitum. They were assigned randomly to control or epileptic groups. Animals in the TLE group were submitted to multiple systemic kainate injections until they reached the status epilepticus, as described previously (Suarez et al., 2012). Animals that did not enter status epilepticus were not included in the study. Control animals were injected with saline in identical fashion and were treated similarly to animals in the epileptic group. We also included some normal, untreated rats in the control group since no differences between these and saline-injected rats were apparent. Procedures met the European guidelines for animal experiments (86/609/EEC). All experiments started $\sim 8$ weeks post-status when kainate-injected rats started to exhibit recurrent seizures. A total of 22 normal rats and 26 TLE rats were used in this study.

Object recognition tasks. The test apparatus consisted of a square open field $(80 \times 80 \times 50 \mathrm{~cm})$ that was situated in an evenly illuminated room (15 lux) with ambient noise masked by a white-noise generator and several spatial cues. Visual cues were visible on the surrounding walls. Rat behavior was monitored with a video camera, and exploration was analyzed off-line with a computer tracking system (Ethovision 1.90, Noldus IT). Nine different objects (in duplicate or quadruplicate) were used. They differed in terms of height $(10-15 \mathrm{~cm})$, base diameter $(8-10 \mathrm{~cm})$, color, shape, and surface texture. In pilot studies, we confirmed that rats showed no preference between these objects. Animals never climbed onto the objects during exploratory tasks. Odor cues were removed after each trial by cleaning objects and the open field with acetic acid at low concentration $(0.1 \%)$.

Animals were handled individually on 4 consecutive days for $4 \mathrm{~min}$ each before starting habituation sessions, consisting of 10 min free openfield exploration three times once a day. On the first day after habituation, rats were tested on the four different tasks using the object recognition paradigm to test the individual components of episodic-like memory [novel object recognition (what), spatial recognition (where), and temporal memory (when)] and to control for object-place recognition memory to ensure that rats can associate objects and places. Each trial consisted of either one or two sample phases ( $3 \mathrm{~min})$, followed by a test phase $(3 \mathrm{~min})$ after an intertrial period of $50 \mathrm{~min}$. The orientation of the objects during the sample trials and the test trial was randomized between subjects and across the different tests within subjects. The interval between tasks was at least $48 \mathrm{~h}$ and the task order was as follows: what, object-place, where, and when. A schematic illustration of each task is represented in Figure 1, as follows: what memory (Fig. $1 A$ ), where memory (Fig. $1 B$ ), when memory (Fig. $1 C$ ), and object-place memory (Fig. $1 D$ ). The episodic-like what-where-when memory task (Fig. 2; Kart-Teke et al., 2006) was performed after animals had been tested on the individual components in the four previous tasks. While the object-place memory task (Fig. $1 D$ ) could resemble the what task (Fig. 1A), it tested for the ability of the rat to associate objects and places, a key capability required to successfully solve the what-where-when task.

In addition, we tested for the effect of two temporally dated sample phases in memory by designing a task to check whether rats had similar access to information from the sample phases when they entered into the test phase of the when and the what-where-when tasks. In this task, animals had to discriminate a novel object from familiar objects that were seen in samples 1 (100 min ago, test 1$)$ and 2 (50 min, test 2; Fig. $1 E$; the position was randomized between animals). If information gathered during sample 1 was neglected or weaker than that of sample 2, then discrimination ratios in test 1 and test 2 will be different. Instead, if animals exhibited similar discrimination ratios for the novel object, then we can argue against rats not recalling information from the first acquisition sample.

A total of 8 control animals and 10 epileptic rats were tested in all the behavioral tasks, except for the task in Fig. $1 E$ where eight control rats and four TLE rats were used. Some additional rats $(n=6$ control, $n=12$ epileptic) were tested in the what-where-when task while being electrophysiologically recorded from the dorsal hippocampus using multisite probes and similar behavioral protocols.

Electrophysiological recordings. Rats were implanted with linear arrays of 16 or 32 channels before the episodic-like memory task under anesthesia with $1.5-2 \%$ isofluorane mixed in oxygen $(400-800 \mathrm{ml} / \mathrm{min})$ and were continuously monitored with an oximeter (MouseOX, Starr Life Sciences). Electrode implantation was performed 8 weeks after kainate treatment, when rats started to exhibit recurrent seizures. Acute surgical treatment included using enrofloxacin $(10 \mathrm{mg} / \mathrm{kg}$, s.c.) and metilprednisolone $(10 \mathrm{mg} / \mathrm{kg}$, i.p.) to prevent infection and inflammation, and the analgesic buprenorphine $(0.05 \mathrm{mg} / \mathrm{kg}$, s.c.). For probe implantation, rats were placed in a stereotaxic apparatus (Kopf Instruments), and their skulls were exposed to perform a craniotomy $1.8 \mathrm{~mm}$ wide at $5.6 \mathrm{~mm}$ posterior to bregma and $4 \mathrm{~mm}$ from midline. Several jewelers' screws were fixed to the skull for implant stability, and ground and reference at the occipital region. Multisite silicon probes (NeuroNexus Tech; site impedance, between 0.3 and $1.2 \mathrm{M} \Omega$; interelectrode distance, $100 \mu \mathrm{m}$ for 16-channel probes, $50 \mu \mathrm{m}$ for 32-channel probes) were implanted either fixed or mounted on an adjustable microdrive [both custom-made or using the nDrive, Neuronexus Tech (http://hippo-circuitlab.com/2013/ 04/microdrive-implanting-procedures-2/)] and advanced under electrophysiological control. The craniotomy and probes were covered with sterile Vaseline, and the microdrive base was cemented in place with dental acrylic (Kemdent). After surgery, the area was dusted with topical antibiotic powder. Experiments did not begin until at least 1 week later.

Electrophysiological recordings were obtained using a unity-gain multichannel headstage with an infrared light-emitting diode (LED) to track the rat's position (Axona). Signals were amplified $400 \times$ and recorded at $4800 \mathrm{~Hz} / 12$-bit precision in a frequency band from 1 to $2400 \mathrm{~Hz}$ after analog filtering (Dacq system, Axona). The positional signal from the LED was stored at $50 \mathrm{~Hz}$ in the $x$ and $y$ coordinates with a spatial resolution of 300 pixels $/ \mathrm{m}$. The time spent by rats exploring different objects during the what-where-when memory task was recorded on-line using the computer keyboard and further analyzed off-line (see below).

Recordings were obtained daily between 8:00 A.M. and 7:00 P.M. over 1-3 weeks. During these sessions, animals were examined for their activity during several behavioral conditions (walking, running, immobility, and sleep) and while undergoing behavioral tasks. Some animals were also continuously videotaped in periods of $48-72 \mathrm{~h}$ for seizure detection. Spontaneous seizures were classified according to the Racine scale (Racine, 1972) as follows: (1) orofacial automatisms (stage 1); (2) head nodding (stage 2); (3) forelimb clonus (stage 3); (4) forelimb clonus with rearing (stage 4); and (5) forelimb clonus with rearing and fallings (stage 5). Electrographic seizures were identified as a typical ictal pattern accompanying convulsive manifestations of stages $2-5$. Interictal spikes were identified as transient sharp waves $>800 \mu \mathrm{V}$ that eventually satu- 
A
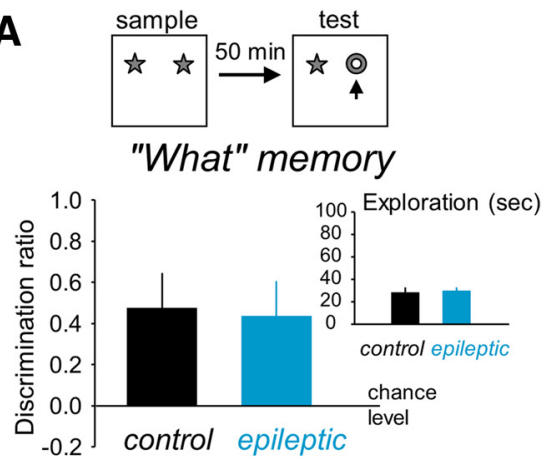

C

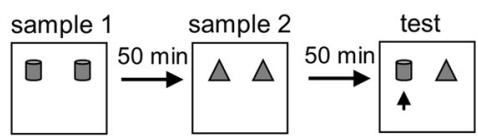

"When" memory

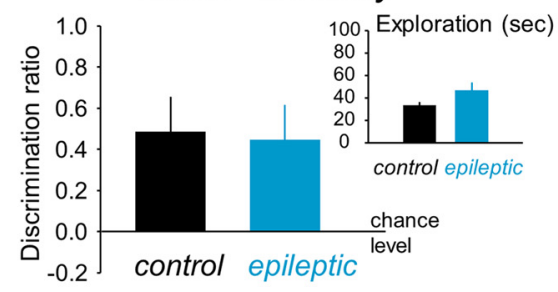

$\mathbf{E}$

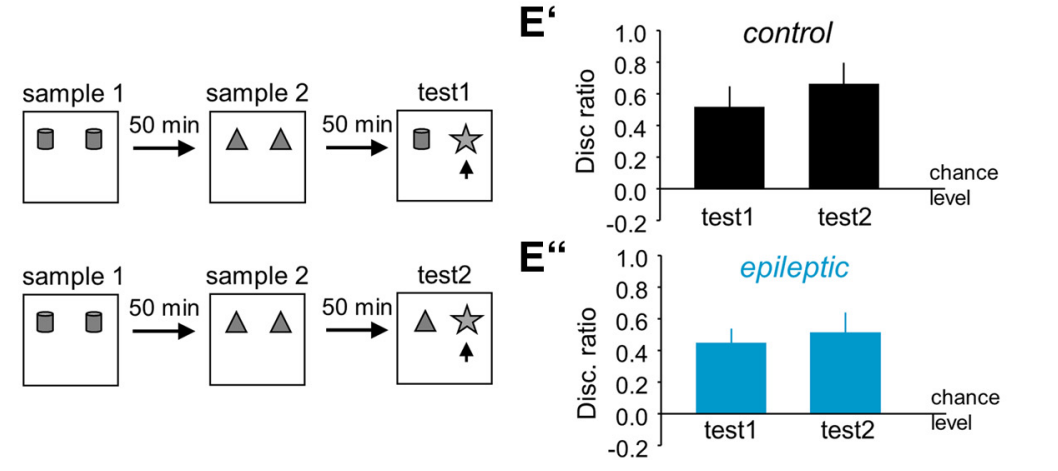

Figure 1. Behavioral data. $A$, To ensure that rats could discriminate between objects and recognize familiar objects after $50 \mathrm{~min}$, they were tested in a novel-object recognition task (what memory). A discrimination ratio was defined as the ratio between the difference in time spent exploring the novel (arrow) versus the familiar object divided by the total exploratory time. The inset shows the total exploration time in the test phase. $\boldsymbol{B}$, We used an object recognition task to test for the ability to discriminate spatial changes (where memory). $\boldsymbol{C}$, The recognition memory of objects encountered in different temporal context (when memory) was tested in a two-sample task with two different objects. $\boldsymbol{D}$, The ability to associate an object and a specific location was tested with an object-place memory task. Discrimination was defined as explained above. $\boldsymbol{E}$, Task to check for the effect of two different temporally dated sample phases on novel object recognition. Exploratory preferences for a novel object (star) were tested against an early (cylinder) or a recent (pyramid) familiar object. $\boldsymbol{E}^{\prime}$, Control animals exhibited consistent exploratory preferences for the novel object independent of whether it was confronted with familiar objects seen at different time frames. $E^{\prime \prime}$, Similarly, TLE rats exhibited similar exploratory preferences for the novel object tested against familiar objects from two different temporally dated samples. Data in $A-D$ are given as the mean \pm SEM ( $n=8$ control, $n=10$ epileptic). Data in E reflect the mean $\pm \operatorname{SEM}(n=8$ control, $n=4$ epileptic). No statistical differences were found between groups for any test.

rate the amplifier in some, if not all, the recording sites. They were typically, but not always, associated with high-frequency oscillations in a wide range from 30 to $800 \mathrm{~Hz}$ (Ibarz et al., 2010; Jefferys et al., 2012).

Histology. After completing the experiments, implanted rats were perfused intracardially with $30 \mathrm{ml}$ of PBS $0.1 \mathrm{M}, \mathrm{pH} 7.3$, with $0.2 \%$ heparin, followed by $200 \mathrm{ml}$ of $4 \%$ paraformaldehyde. Brains were removed, and coronal sections $(20 \mu \mathrm{m})$ were cut on a vibratome to localize the probe track and to confirm features of TLE-associated hippocampal sclerosis. Immunohistochemistry, using a monoclonal anti-NeuN antibody (1:1000, Bachem), was performed on gelatin-coated slides, by the biotin-avidin-peroxidase method, as described previously (Inostroza et al., 2011). Images were taken with a Leica DFC295 camera coupled to a stereomicroscope (S8APO, Leica).

Behavioral data analysis. Proportional differences between exploration times of different objects were examined to evaluate task performance quantitatively. Object exploration was defined as the rat being within $2 \mathrm{~cm}$ of an object, directing its nose at the object, and being involved in active exploration such as sniffing. For each rat, the time spent exploring the test object in the what, where, when, and objectplace memory tasks (Fig. $1 A-D$, arrows) was converted to a discrimination ratio with the following formula:

$$
\begin{aligned}
\left(\text { Object }_{\text {test }}-\text { Object }_{\text {control }}\right) / & \left(\text { Object }_{\text {test }}\right. \\
& \left.+ \text { Object }_{\text {control }}\right) .
\end{aligned}
$$

A discrimination value of zero indicates no preference (chance level); whereas, a positive value indicates a preferential exploration of the test object, and a negative value indicates preferential exploration of the control object (Ennaceur and Delacour, 1988).

For the episodic-like memory task (Figs. 2, 4), we defined a where memory index to quantify exploration of the object that had recently changed location as the proportion of time spent exploring a recent displaced object (B2) against a recent stationary one (B1), in a manner similar to that of DeVito and Eichenbaum, 2010:

$$
\text { Where }=(\mathrm{B} 2-\mathrm{B} 1) /(\mathrm{B} 2+\mathrm{B} 1) .
$$

A when memory index was defined as the proportion of time spent exploring an old stationary object (A1) versus a recent stationary object (B1) according to the following formula:

$$
\text { When }=(\mathrm{A} 1-\mathrm{B} 1) /(\mathrm{A} 1+\mathrm{B} 1)
$$

For these ratios, a value of zero indicates no preference (chance level), whereas a positive value indicates a preferential exploration of the recently displaced object for where and of the old stationary object for when.

To evaluate against chance exploration of objects, we also defined discrimination indices (DIs) in the test phase of the episodic-like what-where-when task (Figs. 2, 4) by dividing the time spent exploring each of the objects by the total exploratory time on all four objects (chance level at 0.25).

Normality was confirmed with the Kolmogorov-Smirnov test. In these cases, data were analyzed with multivariate ANOVA with tasks and objects (discrimination ratios or exploratory times) as the within-subject factors, and groups (control, epileptic) as the between-subject factor. Posterior $t$ tests for independent samples were run to check for difference between groups, and results were considered significant at $p<0.05$ and Bonferroni corrected if required. Data not meeting the normality criteria were compared using nonparametric tests (Wilcoxon signed-rank test). In addition, the main discrimination ratios of each group were compared with chance performance using one-sample $t$ tests. Behavioral data are represented as the mean \pm SEM, unless otherwise indicated.

Electrophysiological data analysis. LFPs from different recording sites on the 16-channel probe were analyzed using routines written in Matlab (MathWorks). Hippocampal strata were identified using information from typical 
LFP events, including the following: (1) multiunit activity to identify the granule cell (GC) layer of the dentate gyrus (DG) and the CA1 stratum pyramidale (SP), which was also identified using information from ripple events; (2) sharp wave events to define the CA1 stratum radiatum (SR); (3) dentate spikes to identify the molecular layer (ML) of the DG; and (4) the spatial distribution of theta oscillations $(4-12 \mathrm{~Hz})$ and gamma activity $(20-90 \mathrm{~Hz})$, which, together with the previous information, allowed us to identify the stratum lacunosum molecular (SLM). Layer identification was confirmed with post hoc NeuN immunostaining. Defective recording sites (one to two in some probes) were linearly interpolated from LFPs at neighboring nondefective sites. Interpolated data were used only to study the spatial expression of spectral indices of the LFP signals. Rats with defective sites at the SLM and ML were not included.

For simultaneous analysis with LFP spectral features, kinematic variables (position, speed, and acceleration of the rat), and keyboard information (object exploration), data were segmented in windows of $1 \mathrm{~s}$. The spectral power (in decibels $10 \cdot \log _{10}$ ) in SLM and ML and the SLM-ML theta coherence $(4-12 \mathrm{~Hz})$ were estimated using the Thomson multitaper method [Thomson, 1982; coherence was calculated using routines by Peter Huybers (http://www.people.fas. harvard.edu/ phuybers/Mfiles)], with two tapers for $1 \mathrm{~s}$ windows in such sliding windows with $50 \%$ overlap, yielding a frequency resolution of 1 $\mathrm{Hz}$. To determine the effect of movement speed on theta power, animal running $(>5 \mathrm{~cm} / \mathrm{s})$ was correlated with indices of theta power and coherence in similar windows. To examine taskdependent modulation of theta activity, spectral and kinematic variables were examined in data segments defined from keyboard information on the exploratory visits to each object, as recorded on-line during the what-where-when task by pressing predefined keyboard letters. The total time spent on each object visit (epoch) was divided by two to define a midpoint for each object exploration episode (Tort et al., 2011). Signals of interest (theta coherence, power, and speed) were then aligned with respect to this midpoint for each epoch (zero time). This procedure allowed the evaluation of both consecutive visits to the same object and the effect of exploration order of different objects over the whole task. Exploration epochs shorter than $1 \mathrm{~s}$ were not included in the analysis. Only whole-session artifact-free data were included in this analysis ( $n=2$ control, $n=2$ epileptic rats).

For quantification and comparison between groups, we first segmented continuous data from the whole recording session ( $300 \mathrm{~s}$ ) to look for segments free of artifacts (typically produced when the animal encountered the walls and the objects) and to exclude short periods of immobility that usually accompany open-field exploration. First, LFP signals from the SLM were Fourier transformed at $0.5 \mathrm{~Hz}$ resolution, and the theta peak frequency was defined as the mean power peak of the average spectrum in the $6-10 \mathrm{~Hz}$ band. The spectral domain was then resampled at $2 \mathrm{~Hz}$ resolution such that a central theta bin was centered on the theta peak frequency previously detected. We chose data segments with clear theta activity, as evaluated by the maximal power at the central theta bin. The $1 \mathrm{~s}$ central part of each of the selected segments was isolated to get a set of $1 \mathrm{~s}$ nonoverlapping segments $(118 \pm 88$ segments per animal). We also confirmed spectral differences (power and coherence) between groups using current-source density (CSD) signals. Data with poor spatial sampling around the SLM and the molecular layers (due to defective sites or poor layer resolution) were not included in this analysis. Isolated defective sites were linearly interpolated from adjacent sites be-

\section{Episodic-like memory}

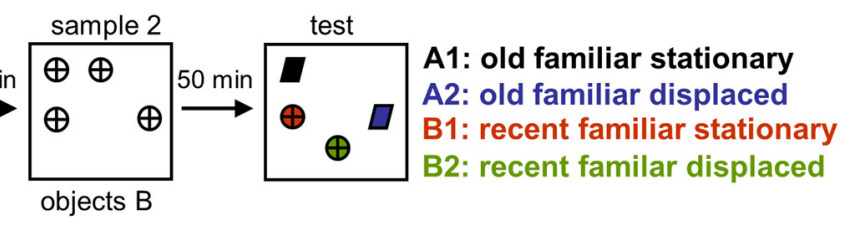

B‘

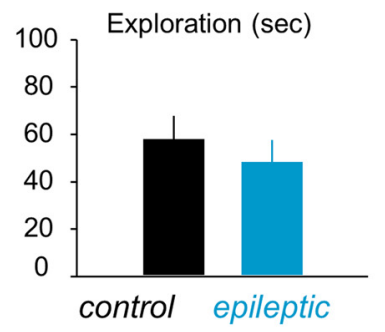

D $D /-B 2$

$D I-A 1$
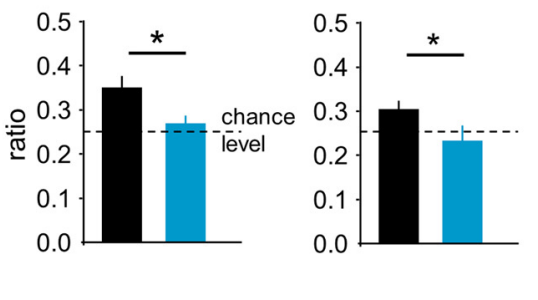

Figure 2. Episodic-like memory task. $\boldsymbol{A}$, The episodic-like memory task consists of two sample phases and a test phase. In each sample phase, rats encountered two sets of four identical novel objects (old objects, sample 1; recent objects, sample 2). In the test phase, objects were mixed together. Two of them were placed in the same location as in sample phases (A1, old-stationary; B1,

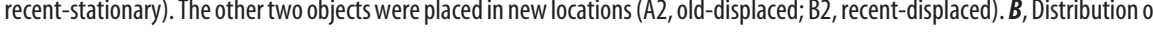
exploratory times per object in the test phase for the control and epileptic groups. $\boldsymbol{B}^{\prime}$, Total exploratory time for each group in the test phase. C, Discrimination index where and when. D, Mean discrimination index for objects A1 (DI-A1) and B2 (DI-B2) from each group. Data are represented as the mean $\pm \operatorname{SEM}\left(n=8\right.$ control, $n=10$ epileptic). ${ }^{*} p<0.05,{ }^{* *} p<0.01$.

fore CSD estimation. One-dimensional CSD profiles were calculated using the second spatial derivative of local field potentials, and no smoothing was applied. Spectral features of CSD signals were analyzed at defined hippocampal strata, using information from relevant events (e.g., sharp waves, dentate spikes), as described above.

The theta frequency peak, theta $(4-12 \mathrm{~Hz})$ and gamma $(30-90 \mathrm{~Hz})$ power, theta coherence, and a theta phase-locking value (PLV) were estimated from data segments selected as described above at a resolution of $1 \mathrm{~Hz}$. The spectral power was given in decibels $\left(10 \cdot \log _{10}\right)$ and calculated using a Hamming window and the fast Fourier transform. Theta and gamma power were defined from the area in the $4-12 \mathrm{~Hz}$ and $30-90$ $\mathrm{Hz}$ bands, respectively. Pairwise theta coherence was defined using the Thomson multitaper method in the band of $4-12 \mathrm{~Hz}$ from the crossspectral power densities (Thomson, 1982). A pairwise PLV was estimated from the Hilbert transform-based analytic signals in the $4-12 \mathrm{~Hz}$ band (noncausal finite impulse response filter and Hamming window; Lachaux et al., 1999). PLV is a measure of the significance of the phase covariance between two signals. The spatial distribution of spectral measurements was evaluated using LFP signals from sites at different strata in the CA1 and the DG, and aligned with respect to the SLM for each animal. We also evaluated spectral indices across the hippocampal regions CA1 and DG as follows: (1) by averaging the theta power at individual sites from each region (all sites at SR and SLM for CA1; sites at ML for DG); and (2) averaging together coherence and PLV values from all site pairs between regions. Kinematic variables, including position, speed, and acceleration, were calculated using similar $1 \mathrm{~s}$ data segments. 
Normality was confirmed using the Kolmogorov-Smirnov test. Variations of spectral and kinematics variables during several epochs of object exploration were evaluated using $z$-score statistics $[z=$ (data mean)/SD), with $z=0$ reflecting epoch data at the population mean $(z=$ \pm 1 for epoch data at SD). Differences between spatial profiles of theta power, frequency, coherence, and PLV were analyzed with a three-way nested ANOVA with group (control or epileptic), task (episodic-like memory or habituation), and sites (9 levels) as factors, and session (18 levels) as an extra factor nested in the group and task factors. Student's $t$ tests for independent samples were used to check for differences between groups and were Bonferroni corrected. Univariate linear regression analysis was performed to study the relationship between spectral variables and behavioral indices. A 95\% confidence interval was estimated using a leave-one-out procedure, excluding one rat (two sessions) at a time. Correlations were evaluated using the Pearson coefficient and the associated Student's $t$ test. In the case of correlations across the entire population (control and TLE rats), significance was rejected whenever the group factor had a confounding effect over the dependent variable; that is, the $R^{2}$ of the regression between electrophysiological and behavioral variables (interchanged as dependent and independent for each test) has to be significantly higher than the $R^{2}$ of the regression between each dependent variable and a binary-coded group variable (binomial test with $p=0.05)$. Data are given as the mean $\pm 1.96 \mathrm{SEM}$ ( $95 \%$ confidence interval), unless otherwise indicated.

\section{Results}

Preservation of individual memories for what, where, when, and object-place associations in experimental TLE

We first tested for the ability of TLE rats to recall in isolation the individual components of episodic-like memory (i.e., what, where, and when memories, together with memory for objectplace associations). Animals were tested with single-trial object recognition tasks at $50 \mathrm{~min}$ intervals between the sample and the test phase. TLE rats $(n=10)$ performed similarly to controls $(n=$ 8 ) in all tasks examined, with discrimination ratios (what, where, when, and object-place) showing no significant interaction $\left(F_{(4,13)}=0.575 ; p=0.719\right.$; Wilks $\lambda=0.81$; Fig. $\left.1 A-D\right)$. We examined the animals' ability to discriminate between objects and found no difference between groups (Fig. $1 A-D$; all comparisons were Bonferroni corrected). Moreover, there was no difference in the total exploration during the test session $\left(F_{(4,13)}=0.744 ; p=\right.$ 0.57 ; Wilks $\lambda=0.744$; Fig. $1 A-D$, insets). Therefore, the ability of TLE rats was unimpaired in independent tests of what, where, when, and object-place memories.

However, it might be possible that the individual when memory task (Fig. 1C) can be reduced to the what task (Fig. 1A), provided that sample 1 is neglected by the animals. This argues against the idea of testing a when memory with two-sample phases, because they could be solved without any temporal reference. To discard such an effect, we implemented a task (Fig. 1E) aimed to check for differences in exploratory preferences between a novel object and familiar objects that were seen in samples 1 (100 min ago, test 1$)$ and 2 (50 min, test 2$)$. We found that both control (Fig. $1 E^{\prime}$ ) and epileptic rats (Fig. $1 E^{\prime \prime}$ ) exhibited similar exploratory preferences for the novel object (star), independently of whether it was confronted with a familiar object seen in sample 1 (cylinder) and sample 2 (pyramid). These data argue against animals not recalling information from the first acquisition sample. Having controlled for this factor, data from the when task (Fig. 1C) confirmed that rats from both groups had access to information gathered from two different time frames, since they explore the object seen in sample 1 (early) more than the object seen in sample 2 (recent). Therefore, the animals kept a sense of timing, potentially reflecting a memory for the elapsed time between the sample and test phases (Roberts et al., 2008).

\section{Specific deficit of the what-where-when memory in TLE}

We then tested for binding of the what-where-when memory triad using a single-trial object recognition task (Fig. 2A), previously shown to test for nonverbal behavioral correlates of episodic memory (Pause et al., 2010). During the task, animals encountered two groups of objects at different times and in different locations. Exploratory times of the control group alone did not meet normality, and therefore nonparametric analyses were applied. Consistent with previous reports in rats (Kart-Teke et al., 2006; Inostroza et al., 2013), normal animals $(n=8)$ exhibited biased exploration spending more time exploring an old familiar object A1 than a recent familiar object B1 that remained stationary (Fig. $2 B$, A1 black vs B1 red; $z=-2.101 ; p=0.036$, Wilcoxon test; Bonferroni corrected, $p=0.025$ ). This confirms that control animals recognized objects explored during separate trials and remembered their order of presentation. Control rats also showed differential exploration of displaced objects, spending more time exploring a recently displaced object $\mathrm{B} 2$ than the stationary object $\mathrm{B} 1$ (Fig. $2 A, \mathrm{~B} 1$ red vs $\mathrm{B} 2$ green; $z=-2.521 ; p=$ 0.012 , Wilcoxon test) and the old displaced object A2 (Fig. 2A, A2 blue vs B2 green; $t=-6.787$; $p<0.0001$ ). Overall, control animals preferred to explore mostly the old stationary object (A1) and the recently displaced object (B2) (Kart-Teke et al., 2006), similar to human control subjects (Pause et al., 2010).

In contrast, TLE rats $(n=10)$ exhibited no clear preference during object exploration, never showing better-than-chance discrimination (Fig. 2B). We then examined the existence of different exploration patterns between groups by considering together the exploratory times of objects A1, A2, B1, and B2 of both control and TLE rats (normally distributed, Kolmogorov-Smirnov test). Multivariate ANOVA with the exploration time for each of the four objects (A1, A2, B1, B2) as the within-subject factor and groups as the between-subject factor revealed a significant interaction $\left(F_{(4,13)}=12.575 ; p=0.0001\right.$; Wilks $\lambda=0.25$; Fig. $\left.2 B\right)$. Canonical analysis suggested that a strong percentage of the variance could be accounted for by the group factor $\left(\eta^{2}=0.774\right)$, indicating different exploration patterns in the control and TLE groups. Post hoc comparisons showed that the differences for object exploration between control and TLE groups were concentrated on objects $\mathrm{A} 1(t=2.23, p=0.0012)$ and $\mathrm{B} 2(t=2.13, p=$ 0.0024 , Bonferroni corrected), even though the total exploratory times of TLE and control rats were similar $\left(p=0.3219\right.$; Fig. $\left.2 B^{\prime}\right)$. No differences between control and TLE rats were found in object exploration during the first two sample phases (data not shown).

We then compared the where and when ratios between groups to evaluate the spatial and temporal components of episodic-like memory. We found significant group differences both for where $(t=$ $2.262, p=0.038)$ and when $(z=-2.843, p=0.004$; Fig. $2 C)$. Furthermore, both ratios were significantly greater than zero (chance level) in control but not in epileptic rats, confirming chance performance in the experimental group. Importantly, the where and when ratios were uncorrelated $(r=-0.013, p=0.961)$. We also confirmed differences of discrimination ratios for A1 (DI-A1) and B2 (DI-B2), accounting for the exploratory preferences for these objects during the test phase of the task (Fig. 2D).

Together, these data indicate that kainate-treated Wistar rats were significantly impaired in episodic-like memory abilities, as tested in the what-where-when task. Importantly, impairment of TLE rats was specific for the integrated what-where-when memory (Fig. 2), whereas they did not exhibit any deficit when the individual components were tested in separate tasks not requiring any binding of spatiotemporal context with an event (Fig. $1 A-D$ ). We previously showed that these epileptic rats were able to solve a complex version 
A control

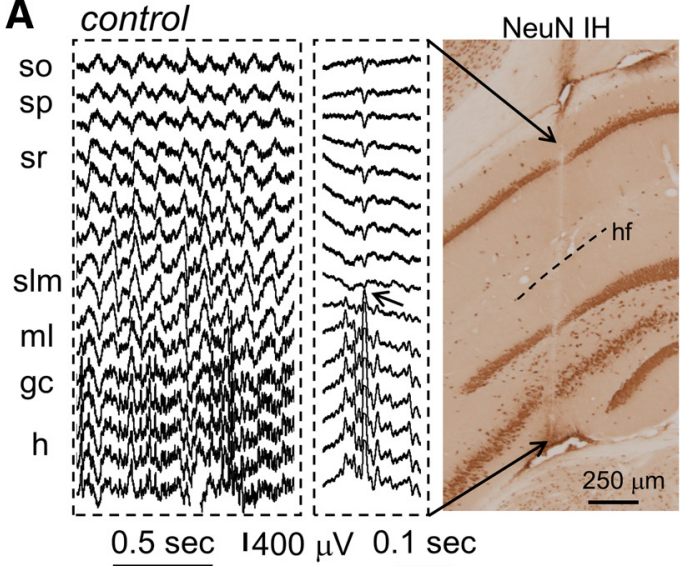

B epileptic

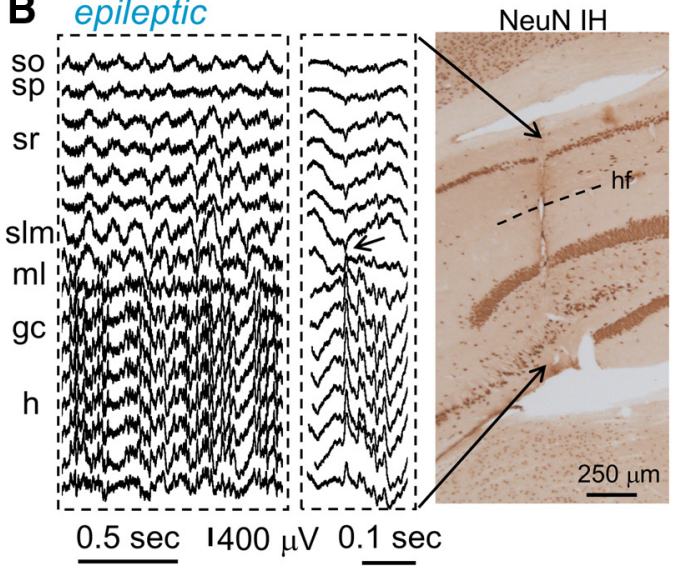

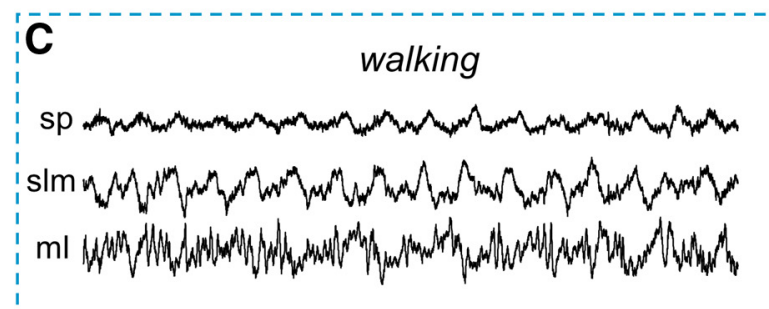

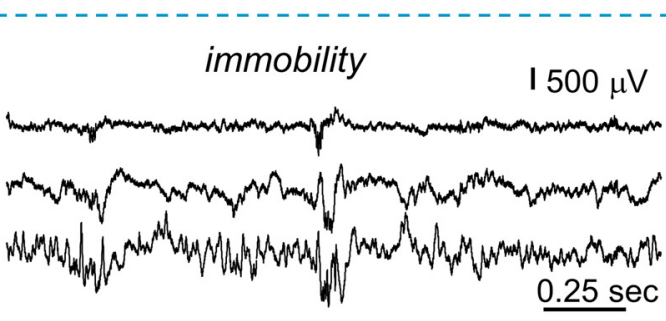

iD

interictal spikes
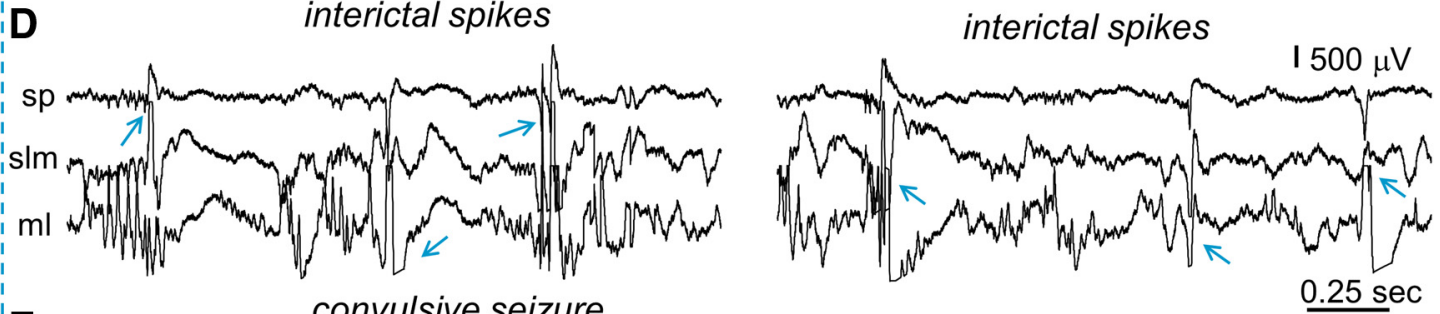

:E

convulsive seizure

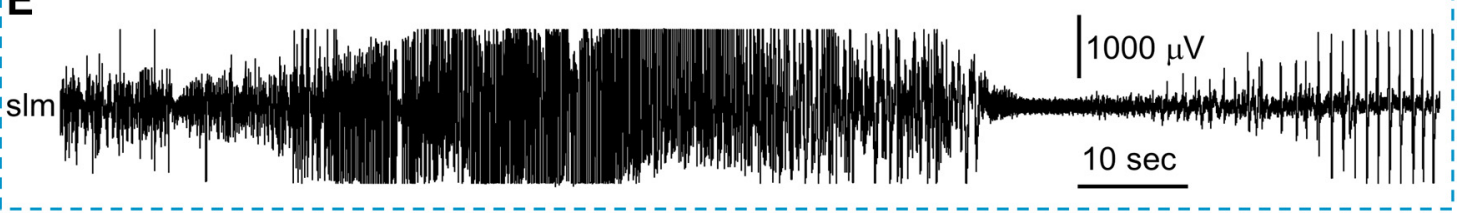

Figure 3. Multisite electrophysiological recordings from behaving animals. $A$, Typical theta activity recorded from the dorsal hippocampus of a normal rat during the episodic-like memory task with a 16-channel probe (left). Middle traces show a representative dentate spike, which changes polarity at the outer molecular layer of the DG. These, together with other typical hippocampal events (sharp wave, ripples, multiunit firing) were used for layer identification. Immunostaining for the neuronal marker NeuN (right) provided further data for localization of hippocampal strata. SO, Stratum oriens; h, hilus; hf, hippocampal fissure. Arrows indicate the probe track. B, Representative epochs of theta activity (left) and a dentate spike (middle) from an epileptic rat. NeuN immunostaining (right) was used in epileptic rats to reveal some histopathological features of temporal lobe epilepsy. Note neuronal loss and hippocampal atrophy, and the probe track (arrows). C, Representative hippocampal activity from another epileptic rat recorded during walking (left) and immobility (right). For clarity, only recording sites at SP, SLM, and ML are shown. Note the high-frequency oscillations at the ML and the maximal theta amplitude at the SLM during walking, while much irregular activity is typically recorded during immobility, similar to that in normal rats. D, Epileptiform events in the form of interictal spikes (blue arrows) were also recorded in these epileptic rats. $\boldsymbol{E}$, Convulsive seizures were accompanied by typical electrographic patterns, as recorded in the SLM. The discontinuous blue-line groups data obtained from the same epileptic rat.

of an object recognition task with a 5 min retention interval (Suarez et al., 2012) and the allocentric version of the water maze (Inostroza et al., 2011), suggesting they were able to manage high cognitive loads. Therefore, failure in the what-where-when task points to specific dysfunction of TLE rats to integrate spatial and temporal aspects of events when tested at once.

Simultaneous recordings of hippocampal local field potentials exclude seizure-related subclinical confounding factors

A major concern regarding interpretation of behavioral data is whether epileptic rats were expressing epileptogenic activity, including interictal spikes, electrographic seizures, and any other subclinical activity that eventually interfered with their cognitive performance (Aldenkamp, 1997; Holmes and Lenck-Santini, 2006). To investigate this, we implanted linear arrays of multisite silicon probes before the task in an independent group of animals $(n=6$ control, $n=12$ epileptic) to record simultaneously from several strata of the dorsal hippocampus while they performed the episodiclike memory task (Fig. 3). Recording sites were defined with respect to hippocampal strata using information from relevant electrographic events (sharp waves, ripples, dentate spikes, multiunit firing; see Materials and Methods) and post hoc NeuN immunostaining (Fig. $3 A, B$ ). Hippocampal sclerosis in epileptic animals was evident as cell loss in the CA1, CA3, and hilar regions (Fig. 3, compare $B$, right, $A$, right; see also Inostroza et al., 2011).

Laminar LFP recordings from control rats showed the characteristic profile of activity, with theta oscillations dominating 
A

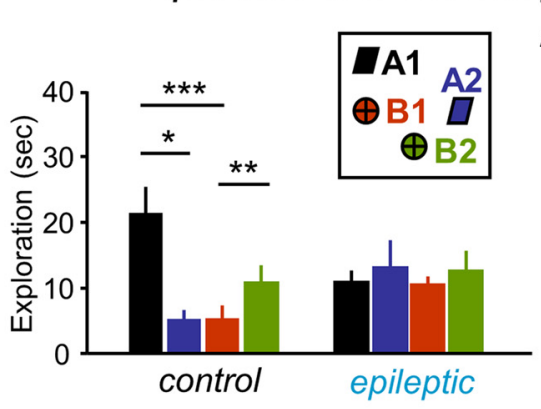

$A^{6}$

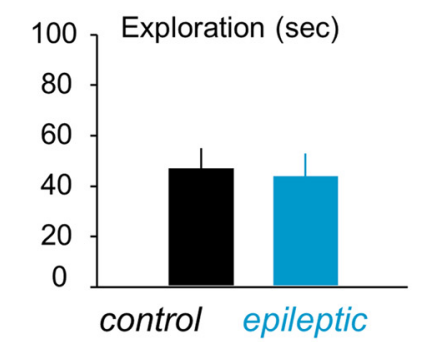

B

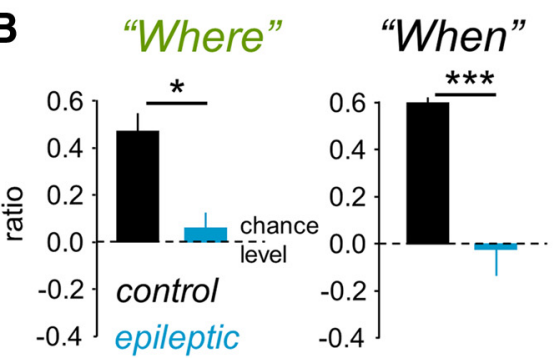

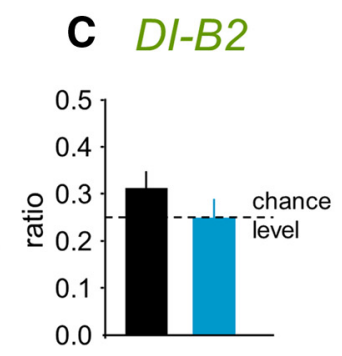

Figure 4. Performance of implanted rats during the episodic-like memory task. $\boldsymbol{A}$, Distribution of exploratory times per object for the control and epileptic groups. Inset represents the object configuration in the task. $\boldsymbol{A}^{\prime}$, Total exploratory time for each group in the test phase. $\boldsymbol{B}$, Mean discrimination index for where and when from each group. $\boldsymbol{C}$, Mean discrimination index for object $A 1$ (DI-A1) and B2 (DI-B2) from each group. Data are represented as the mean \pm SEM ( $n=6$ control, $n=9$ epileptic). ${ }^{*} p<0.05$, ${ }^{* *} p<0.01,{ }^{* * *} p<0.005$.

periods of exploratory behavior (Fig. $3 A$ ) and sharp wave ripples (data not shown) typically present during awake immobility. We found similar LFP activity in all epileptic animals (Fig. 3B), but periods of control-like electrographic activity in a given TLE rat (Fig. 3C) were intermixed with periods (hours and days) dominated by interictal spikes (Fig. 3D) or convulsive seizures (Fig. 3E; Suarez et al., 2012, their Fig. 1). To further discard seizure-related effects, we excluded from this study those TLE rats experiencing any kind of epileptiform event $2 \mathrm{~h}$ before and after the episodiclike memory task ( $n=3$ of 12 epileptic rats).

We next examined the performance of rats implanted with multielectrodes in the episodic-like memory tasks (Fig. 4). Implanted control rats $(n=6)$ exhibited exploratory preferences for objects A1 and B2, while implanted TLE rats $(n=9)$ showed no clear preference during object exploration (Fig. $4 A$ ), as described previously for nonimplanted animals (Fig. $2 B)$. No significant differences were present in the total exploration time between groups (Fig. $4 A^{\prime} ; t=0.181, p=0.859$ ). Importantly, the where and when ratios of implanted rats had an appearance similar to those previously reported for animals tested exclusively using behavioral approaches (Fig. 4B). Implanted TLE rats differed significantly from control animals in discrimination of A1 $(t=5.87, p<0.0001)$, although they did not reach significance for the discrimination ratio of B2 $(t=$ 1.23, $p=0.241$; Fig. $4 C)$. However, implanted TLE animals explored at chance both A1 $(t=1.37, p=0.207)$ and B2 $(t=$ $0.61, p=0.953)$, confirming their poor performance in the what-where-when task compared with controls. Importantly, interictal spikes, nonconvulsive seizures, and other subclinical epileptiform events were not recorded in this set of TLE rats during task performance, which confirms that deficits in the what-where-when task represent an intrinsic cognitive dysfunction of these TLE animals.

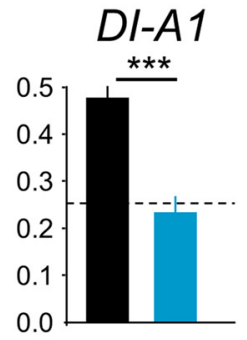

Specific alteration of hippocampal theta activity in TLE rats

Given the major role attributed to the hippocampus in episodic memory, we next analyzed local field potentials recorded in these animals while they performed the test phase of the what-when-where memory task. We carefully chose rats having multisite probes of similar spatial electrode patterning and implanted at comparable levels in the dorsal hippocampus with no defective recording sites at the SLM and ML (four of six controls; five of nine TLE rats).

LFPs recorded during the task showed a dominant theta rhythm in both control (Fig. 5A) and TLE rats (Fig. 5B). Maximal theta power was detected around the hippocampal fissure at the SLM (Fig. 5C), while gamma oscillations were more prominent deep into the DG (Fig. 5D). Interestingly, we found a significant group difference in the spatial profile of theta power $\left(F_{(1,14.9975)}=\right.$ 17.8749, $p<0.001$; for example at SLM: control, $115.56 \pm 0.83 \mathrm{~dB}$; epileptic, $109.31 \pm 2.02 \mathrm{~dB}$; Fig. $5 C)$, but not of gamma activity $\left(F_{(1,14.9975)}=0.5914, p=\right.$ 0.4538; Fig. 5D). We also found group differences in the delta band $(1-4 \mathrm{~Hz})$ at SLM $(t=2.8583, p=0.0064$ for windows of $1 \mathrm{~s} ; t=2.4328, p=0.0143$ for windows of $5 \mathrm{~s}$ ), but due to typical contamination of this band in the freely moving tethered preparation, potential differences between groups could not be interpreted. The difference in theta power was not likely to be associated with different levels of $1 / \mathrm{f}$ noise between groups; that is, no group differences of the $1 / \mathrm{f}$ slope $(t=1.018, p=0.1645)$ and intercept $(t=1.223, p=0.1221)$. Indeed, theta power normalized by the $100-300 \mathrm{~Hz}$ band exhibited similar group differences, as previously described $\left(F_{(1,14.9976)}=43.1287, p<0.0001\right)$. Moreover, we confirmed group differences of the normalized theta power for both LFP $\left(F_{(1,14.0369)}=65.5884, p<0.0001\right)$ and CSD signals $\left(F_{(1,14.0124)}=\right.$ $7.2764, p=0.0173$ ) along the different hippocampal strata, confirming the local nature of theta impairment.

The dominant frequency of theta activity was significantly lower in epileptic animals $(7.47 \pm 0.13 \mathrm{~Hz})$ when compared with controls $\left(8.023 \pm 0.19 \mathrm{~Hz} ; F_{(1,14.9975)}=19.5549 ; p<0.0005\right.$; Fig. $5 E)$, further confirming the specific impairment of hippocampal theta oscillations in TLE animals. Differences in motor activity did not account for theta impairment, since both control and TLE animals explored objects and the open field with similar speed $\left(F_{(1,15)}=0.3558 ; p=0.5598\right.$; Fig. $\left.5 F\right)$ and acceleration $\left(F_{(1,15)}=0.1656 ; p=0.6898\right.$; data not shown $)$. Importantly, coordination of theta activity between SLM and sites at DG, defined by the theta coherence (Fig. 5G) and PLV as a measure of theta phase synchronization (Fig. $5 H$ ), was impaired in TLE animals (coherence: $F_{(1,15.0350)}=6.4884 ; p=0.0223$; PLV: $\left.F_{(1,15.0436)}=7.9323 ; p=0.0131\right)$. Post hoc comparison showed that differences were maximal and significant for recording sites at $200 \mu \mathrm{m}$ below the SLM, corresponding to the ML of the DG $(t=2.8966, p=0.0232$ for coherence, Fig. $5 G ; t=2.7427, p=$ 0.032 for PLV, Fig. 5H; Bonferroni-corrected Welch's $t$ tests). Theta power values at SLM and SLM-ML coherence were not 
A

A control

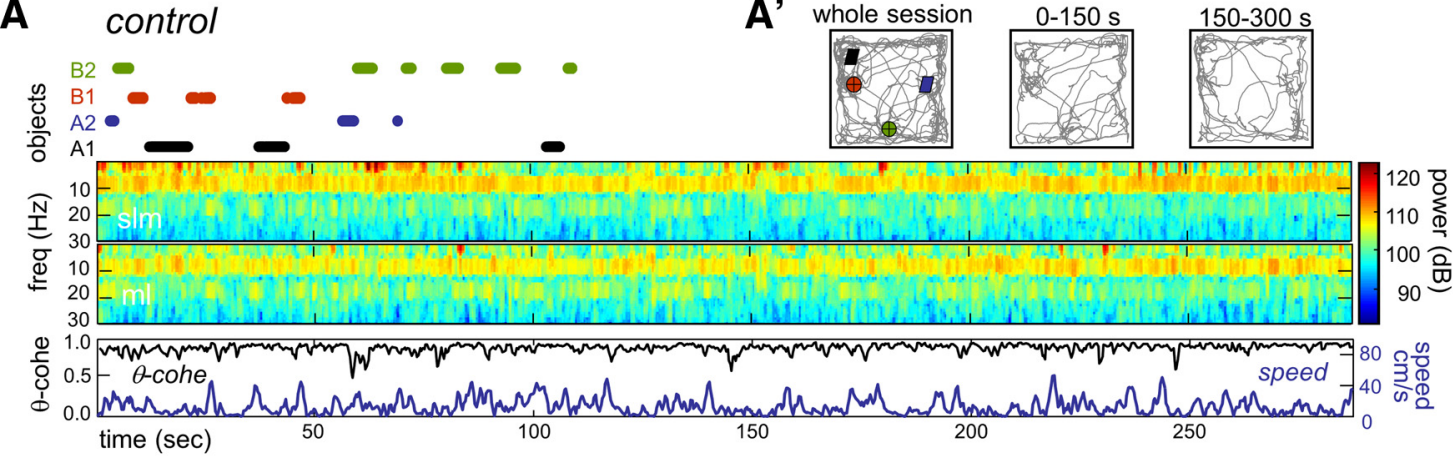

B

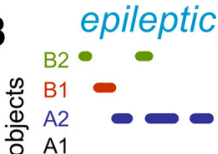

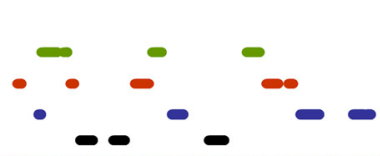

B'
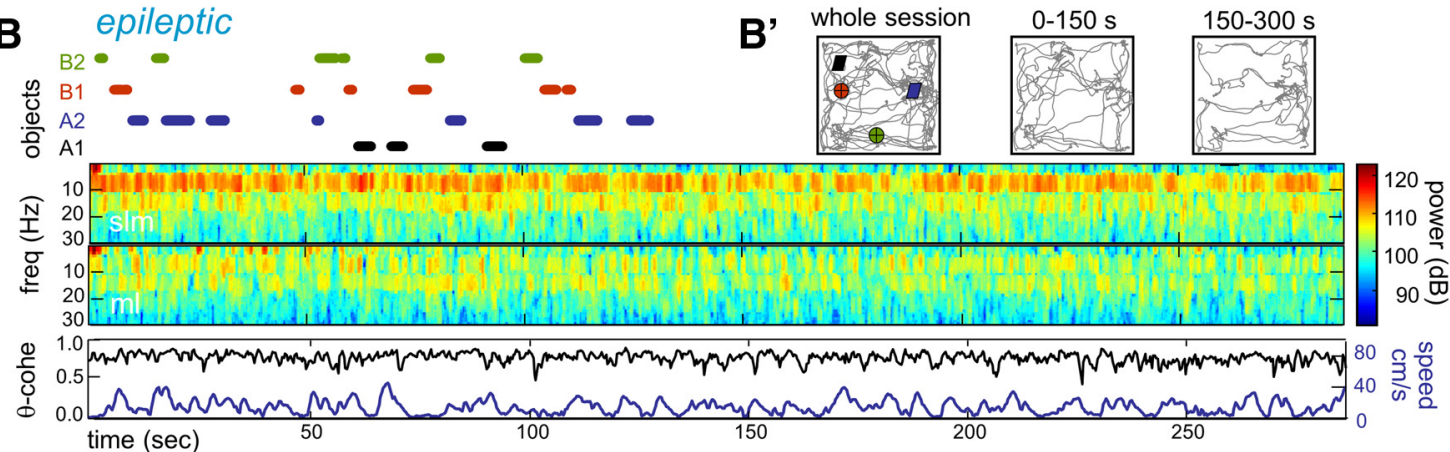

C

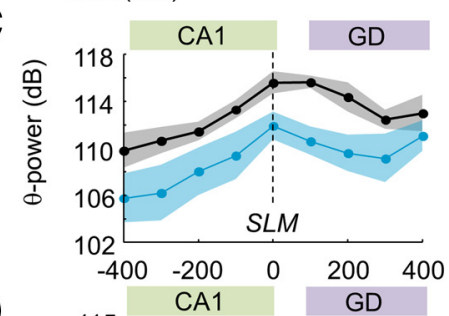

E

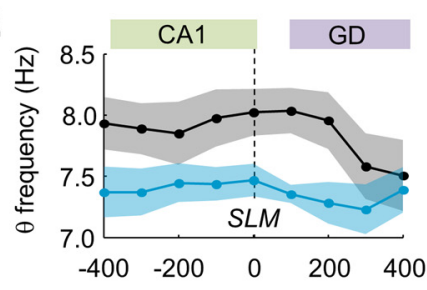

G

D

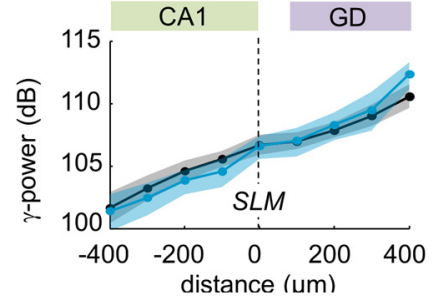

$F$

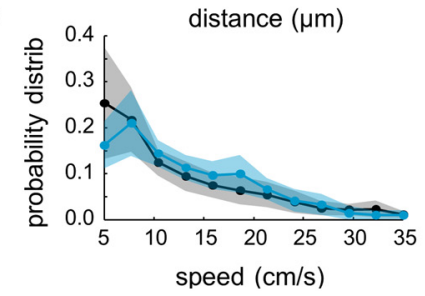

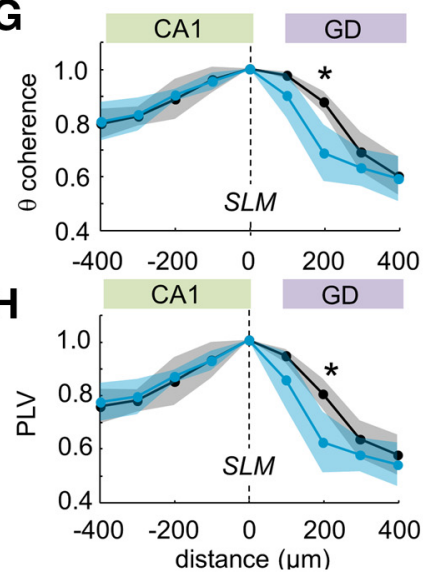

Figure 5. Specific alteration of hippocampal theta activity in TLE. $A$, Performance of a control rat during object exploration (objects) in the episodic-like memory task. The time-frequency power spectrum of hippocampal field potentials at the SLM and the ML is shown for the 1-30 Hz frequency band, together with animal speed (blue trace) and SLM-ML theta coherence (black trace). $\boldsymbol{A}^{\prime}$, Tracking of the position of the animal in the open field for the whole session and each half-session. $\boldsymbol{B}, \boldsymbol{B}^{\prime}$, Same as in $\boldsymbol{A}$ and $\boldsymbol{A}^{\prime}$ for an epileptic rat. C, Spatial profile of theta power (10 -12 Hz) around the SLM of CA1 (data from $n=4$ controls, $n=5 \mathrm{TLE}$ rats). Shadowed areas represent the $95 \%$ confidence interval. $\boldsymbol{D}$, Spatial profile of gamma power ( $30-90 \mathrm{~Hz})$ around the SLM from the same rats as shown in C. E, Spatial distribution of the mean frequency peak of theta oscillations as recorded around the $S L M$. $F$, Probability distribution of animal running $(>5 \mathrm{~cm} / \mathrm{s})$ during the entire task. $G$, Spatial distribution of theta coherence referred to SLM. Note the similar theta coherence values for sites within the CA1 region in both groups, but the large difference in theta coherence between SLM and channels in the dentate gyrus, maximal at $200 \mu \mathrm{m}$ from the SLM (asterisk). $\boldsymbol{H}$, Spatial distribution of PLV at the theta band (10 -12 Hz) referred to SLM. Similar to theta coherence, note maximal differences between groups at $200 \mu \mathrm{m}$ deep from the SLM (asterisk). Data are given as the mean \pm 1.96 SD (95\% confidence interval).

correlated $(r=0.15, p=0.4028)$, emphasizing that they were independently modulated. Contamination from common signals (i.e., volume conduction, common referenced voltage) cannot account for this effect, since group differences for coherence between SLM and ML were confirmed in CSD signals $(t=3.322$, $p=0.0031)$. Since SLM and ML receive direct inputs from the entorhinal cortical layers III and II, as well as from the contralateral hippocampus, our data point to a specific discoordination of these inputs as a potential substrate for episodic-like memory dysfunction in TLE animals. Thus, coordination of theta oscillations may be critical for the retrieval of single events, as has been similarly reported for alternation tasks (Jones and Wilson, 2005; Montgomery et al., 2009; Tort et al., 2009; Benchenane et al., 2010; Sigurdsson et al., 2010).

\section{Theta rhythmopathy reflects a basal condition of TLE hippocampus}

We then asked whether the evolution of theta activity at SLM and ML (generically defined as $200 \mu \mathrm{m}$ below the SLM) and SLM-ML theta coherence along the task were directly related to the preference of the animal for specific objects. We tested this point by looking at the temporal relationship between theta activity and ongoing exploration in the test phase of the what-where-when task. We focused our analysis on the exploration epochs for each object, as defined by keyboard markers during the task (see Materials and Methods) in two controls and two TLE rats showing artifact-free recordings in the entire session. We found no clear statistical trend in SLM-ML theta coherence (Fig. 6A,B), or between SLM and ML power (data not shown), 
A control

Object A1 Object A2 Object B1 Object B2
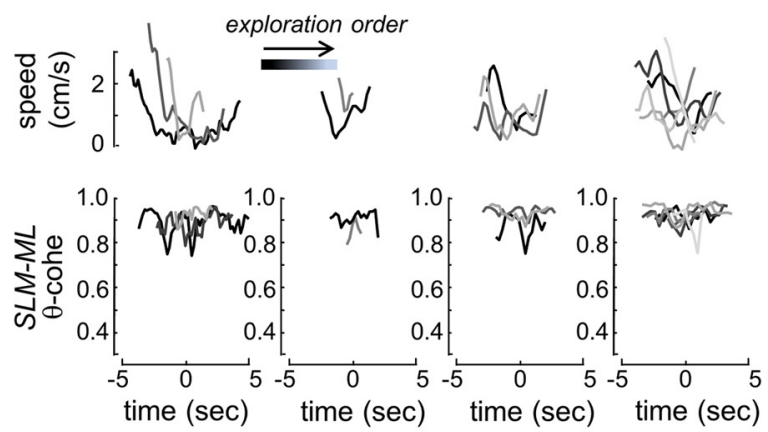

\section{$A^{4}$}

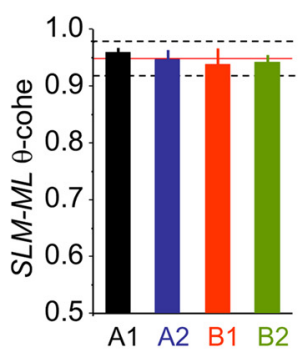

epileptic

B

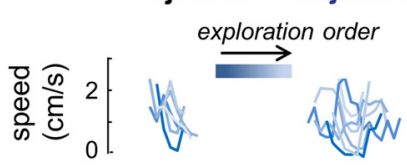

Object B1 Object B2
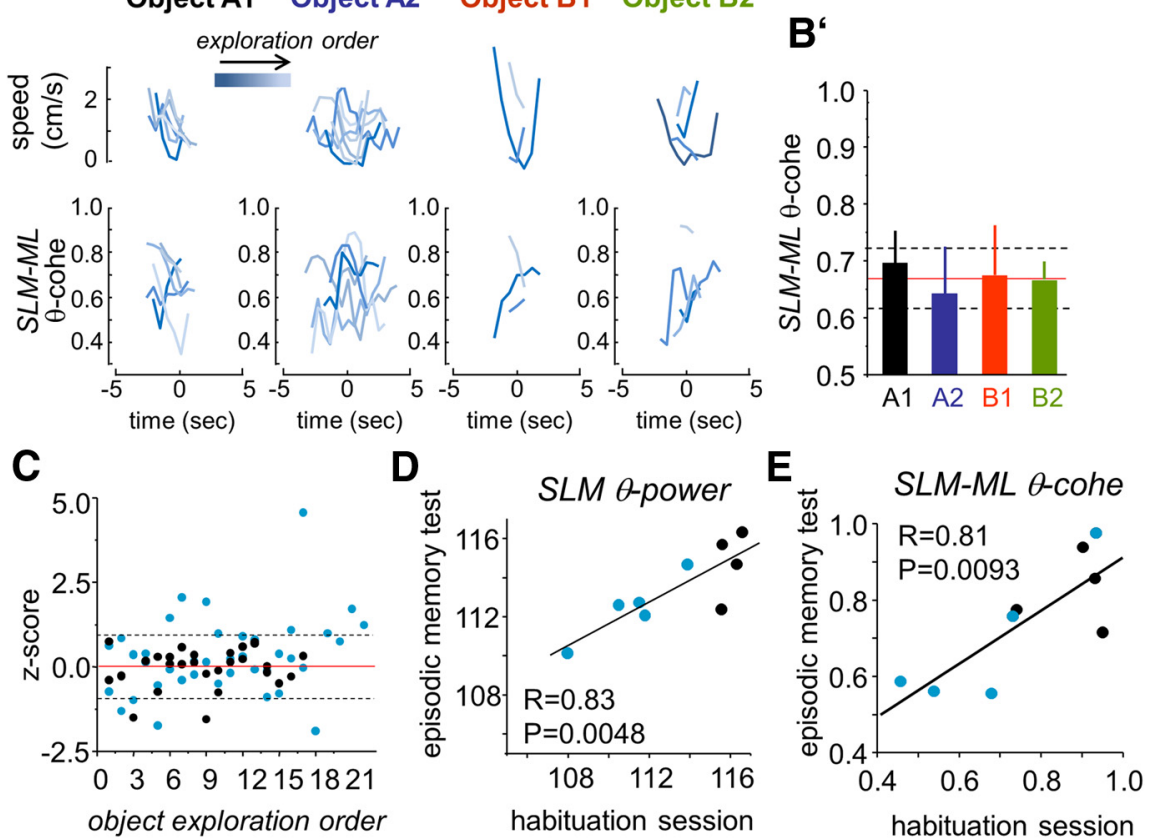

Figure 6. Basal organization of theta activity. $A$, Example, for a control animal, of speed and theta coherence during exploration of each different object in the episodic-like memory task. The exploratory order for each object is represented with colors ranging from black to gray. $\boldsymbol{A}^{\prime}$, Mean values of theta coherence per object were within the mean (red line) and SD (discontinuous line) for the whole session. $\boldsymbol{B}, \boldsymbol{B}^{\prime}$, Same as in $\boldsymbol{A}$ and $\boldsymbol{A}^{\prime}$ for a representative epileptic rat. $\boldsymbol{C}$, Changes of theta coherence for control (black, $n=$ 2) and epileptic rats (blue, $n=2$ ) represented as the $z$-score over successive object explorations. Note that there is no clear divergence from the mean value (red line) from the whole session. The discontinuous line represents the normalized SD. $\boldsymbol{D}$, Correlation between the mean SLM theta power in two different recording sessions (i.e., a habituation session without objects and the episodic-like memory test phase). $\boldsymbol{E}$, Correlation between the mean SLM-ML theta coherence in the two different sessions. $R$ and $P$ refer to values of Pearson correlation.

as rats explored different objects. Indeed, the mean SLM-ML coherence during all individual exploratory epochs for each object was not different from the mean SLM-ML coherence for the whole session, in both control and TLE rats (Fig. $\left.6 A^{\prime}, B^{\prime}\right)$. We also tested whether there was temporal evolution of SLM-ML theta coherence as the rat completed the episodiclike memory task by considering the object exploration order. We found no divergence from the mean value for the whole session in either group (Fig. 6C).

While firm conclusions cannot be made from this reduced database, this task independence indicates that theta rhythm disruption is a basal condition of the chronic epileptic hippocampus, as previously suggested (Dugladze et al., 2007; Chauvière et al., 2009; García-Hernández et al., 2010; Froriep et al., 2012). This effect was further confirmed in the extended dataset: the mean value of spectral indices in the first half of the test $(0-150 \mathrm{~s})$ was similar to the mean value obtained for the second half $(150-300 \mathrm{~s} ; p>0.05$, paired $t$ test). We also detected a strong correlation between spectral indices during the episodic-like memory task and that of any preceding habituation session to the open field without objects, for both the SLM power $(r=0.83, p=0.0048$; Fig. $6 D)$ and SLM-ML theta coherence $(r=0.81$, $p=0.0093$; Fig. $6 E$ ). Importantly, the linear regression of spectral indices for a given animal in the two sessions was significantly adjusted to the identity line for both the SLM power $\left(R^{2}=0.63, p=0.001\right.$; permutation test) and SLM-ML theta coherence $\left(R^{2}=\right.$ $0.67, p=0.0093$; permutation test), further confirming that spectral measurements were consistent between sessions. Similar results were obtained for CA1-DG theta coherence, as defined by averaging coherence values from all site pairs between regions (see Materials and Methods; data not shown). Hence, disrupted coordination of LFP theta activity between CA1 and DG appears to reflect a basal condition of the chronic TLE hippocampus.

\section{Disruption of hippocampal theta correlates with performance in the what-where-when memory task} We next asked whether the degree of theta impairment was linked to performance in the what-where-when task. To accomplish this, we examined the relationship between indices of theta activity and the animal's preferential exploration of objects A1 ("old stationary") and B2 ("recently displaced"), as measured with the where, when, and object discrimination ratios. We used spectral data from two sessions per animal (a habituation session and the episodic-like memory test phase) to increase statistical power, given the consistency of these measurements across sessions.

We found correlation between both the power of theta at SLM and where $(r=0.77, p<0.0002$; Fig. $7 A$, red line), and between SLM theta power and when $(r=0.77, p<0.0005$; Fig. $\left.7 A^{\prime}\right)$. Correlation between SLM theta power and where was significant for the epileptic group alone $(r=0.83, p=0.0028$; Fig. $7 A$, blue line) but not for the control group, probably due to homogeneity and the small data sample. Clustering of epileptic and control data in the SLM power-when plot exhibited a confounding effect on correlation that was not significant for either group alone (Fig. $7 A^{\prime}$ ). Theta coherence between CA1 and DG sites was not correlated with where or when (Fig. $7 B, B^{\prime}$ ). Since the group variable had a strong confounding effect in these correlations, we chose to correlate spectral data with discrimination indices for objects A1 and B2.

Consistent with previous interaction between the SLM theta power and where, we found strong correlation between SLM 
theta power and the rat's discrimination ability for object B2 (DI-B2), which represents mostly spatial information (Fig. 7C). No interaction was detected between the SLM theta power and the discrimination index for object A1 (DI-A1; Fig. $7 C^{\prime}$ ), which mostly represents temporal information. Importantly, we found interaction between theta coherence and DI-A1, but not DI-B2 $\left(r=0.64, p=0.0038\right.$; Fig. $7 D, D^{\prime}$, red line). This interaction was also present for the control group alone $(r=0.73, p=0.0375$; Fig. $7 D^{\prime}$, black line), but not for the epileptic group.

To further confirm the statistical significance of these correlations we used a leave-one-out procedure by excluding one rat (two sessions) at a time and estimating the 95\% confidence interval of the Pearson correlation. To exclude the confounding effects of the group variable, we imposed strict criteria by rejecting significance whenever the group factor had a confounding effect over the dependent variable (see Materials and Methods). We confirmed the specific interaction between theta power and the spatial component of the what-where-when task, as evaluated by DI-B2 (Fig. 7E), and between theta coherence and the temporal component, as evaluated by DI-A1 (Fig. 7F). Correlation between theta power and DI-B2 was strong $\left(R^{2}>0.7\right)$ and significant along the CA1 and DG strata for both groups together and for the epileptic group alone (Fig. 7E, red and blue asterisks, respectively). In contrast, both theta coherence (and PLV; data not shown) between sites at CA1 and DG were strongly correlated only with DI-A1 $\left(R^{2}>0.6\right)$ for both groups together and for the control group alone (Fig. $7 F$, red and black asterisks, respectively). Variability of intragroup correlations is likely to be attributed to the small data sample. Therefore, the power and coordination of hippocampal theta activity might be playing distinct roles in retrieving the spatial and temporal components of episodic-like memory, as tested in the what-where-when task.

\section{Discussion}

Altogether, our data provide novel insights into the neuronal mechanisms of episodic-like memory and how these are degraded in neurological disease. TLE animals exhibited a highly specific impairment of episodic-like memory for the whatwhere-when triad that did not affect memory for the individual what, where, and when components when tested alone. This disruption was associated with a decrease of theta oscillatory power and its coordination, as measured in the local field potentials recorded along the CA1-DG axis. Reduction of theta coordination (both coherence and PLV) was maximal between the SLM of CA1 and the ML of the DG, which receive direct inputs from upstream entorhinal cortical layers and the contralateral hippocampus. Theta power was more correlated with the spatial (where and DI-B2 indices) than with the temporal component of the what-where-when task (when) for both groups and for the epileptic group alone. Instead, measures of theta coordination were associated with the temporal component for the discrimination index DI-A1, but not for when. We conclude that episodic-like memory, as tested in the what-where-when task, is specifically affected in this experimental TLE model and that the impairment of hippocampal theta activity might underlie this dysfunction.

Testing episodic-like memory processes in animals remains challenging. While the what-where-when task potentially allows for evaluation of episodic-like memory by combining both spatial and temporal aspects, it may still not be sufficiently specific. This task, as well as the task testing for when memory (Fig. 1C), relies on comparison of the order of presentation of the objects, instead of on the evaluation of the absolute time an event oc- curred, which is central to episodic memory definition (Tulving and Markowitsch, 1998). It might be argued that while such a sequential exposure to objects could engage episodic-like memory processes, it does not necessarily require them, and that the animal behavior in these tasks could be explained by different decay of memory traces. However, we confirmed similar preferences of control and TLE rats for a novel object when compared with objects seen in an earlier or a more recent sample (Fig. 1E). While these data do not fully discard a recency effect and do not test for spatial information, they argue against rats not recalling information from the first acquisition sample when the when component is tested. Moreover, the failure of TLE rats to solve the what-where-when task was not likely to be attributed to a nonspecific inability for high cognitive loads, since we previously showed they were able to learn an allocentric version of the water maze and a complex version of an object recognition task (Inostroza et al., 2011; Suarez et al., 2012). Instead, our data point to specific impairment of the neuronal processes involved in episodic-like memory, as tested with the what-where-when task.

Over the recent years, data have accumulated to support a dissociation between the mechanisms underlying spatial memory and the memory for the temporal order of events (Eacott and Norman, 2004; Hunsaker et al., 2008; Langston and Wood, 2010; Place et al., 2012). Genetic, lesional, and pharmacological approaches have suggested a role for CA1 in processing short-term temporal order information (Huerta et al., 2000; Kesner et al., 2005). Instead, CA3 appears to be more engaged in integrating contextual representations by tuning spatial information of CA1 place cells (Nakashiba et al., 2008; Hunsaker and Kesner, 2008; Nakazawa et al., 2003). However, the picture is rather more complex, with distinct dorsal-to-ventral contributions (Hunsaker and Kesner, 2008) and intricate interactions between plasticity signaling cascades (Tsien et al., 1996; Huerta et al., 2000; Place et al., 2012; Suarez et al., 2012) and input pathways (Nakashiba et al., 2008; Suh et al., 2011). Using a TLE model with minor extratemporal lesions, we found a specific impairment of what-wherewhen episodic-like memory abilities (Figs. 2, 4). Importantly, spectral analysis of simultaneously recorded hippocampal theta activity showed that theta power correlated more with the spatial than with the temporal component of the task, while measures of theta coordination were more correlated with the temporal component.

Theta oscillations occur in the hippocampus and parahippocampal cortices while the animal explores the environment, and these have been mechanistically related with neuronal processes of encoding and retrieval (Buzsáki, 2002; Kaplan et al., 2012). Precisely tuned theta rhythms appear to be indispensable for generating spatial firing representation of place and grid cells (Koenig et al., 2011; Brandon et al., 2011). Reduction of theta power by septum inactivation results in disorganization of spatial firing maps and potentially disrupts spatial memory (Leutgeb and Mizumori, 1999). Theta oscillations appear to coordinate neuronal activity from different regions during the performance of spatial alternation tasks (Jones and Wilson, 2005; Montgomery et al., 2009; Tort et al., 2009), and a robust increase of coherence among hippocampal subfields, prefrontal cortex, and striatum is likely to accompany learning progression (Tort et al., 2009; but see Sabolek et al., 2009; Sigurdsson et al., 2010). Indeed, in spatial alternation tasks, theta coherence exhibits a particular reorganization of the inter-regional phase relationship, potentially reflecting plasticity changes of functional connectivity between areas (Benchenane et al., 2010). Therefore, both features of theta (i.e., oscillatory power and coordination) could be linked with 


\section{SLM $\theta$-power}

A

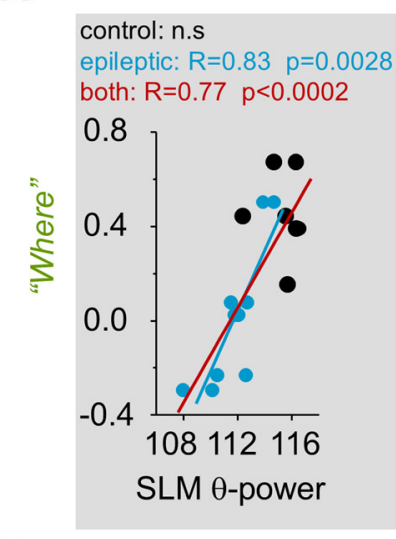

C

control: n.s

epileptic: $R=0.79 \quad p=0.0062$

both: $R=0.74 \quad p<0.0005$

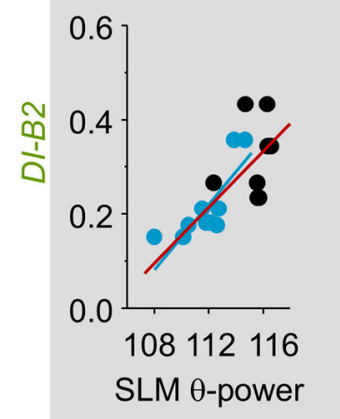

$A^{*}$

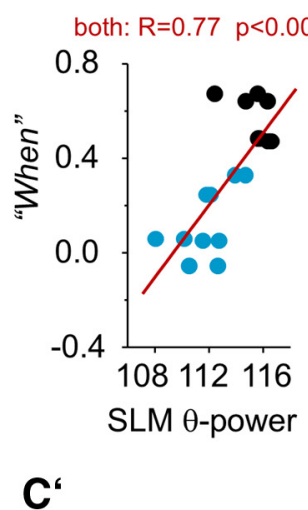

C“

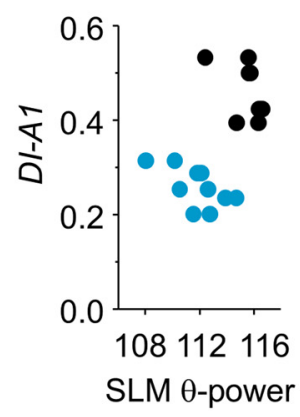

\section{CA1-DG $\theta$-coherence}

B

B'
E

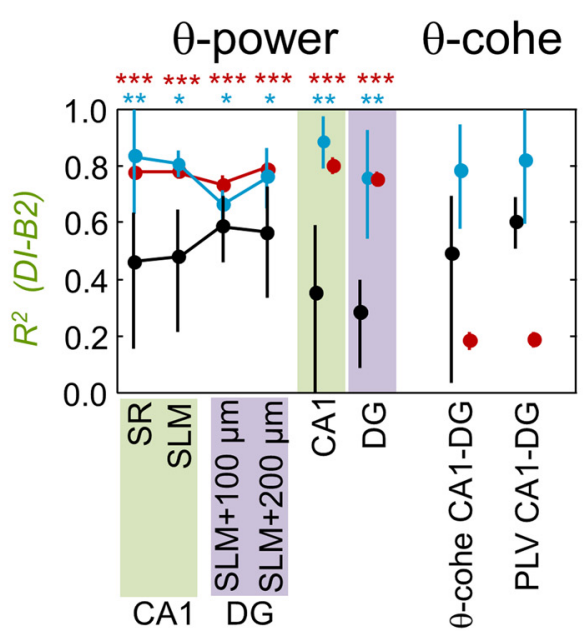

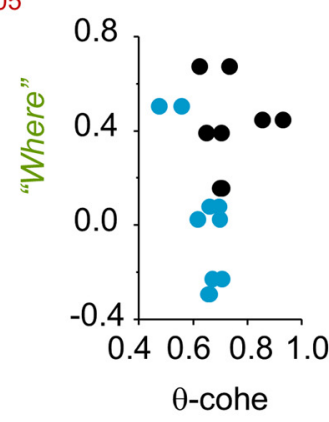

D

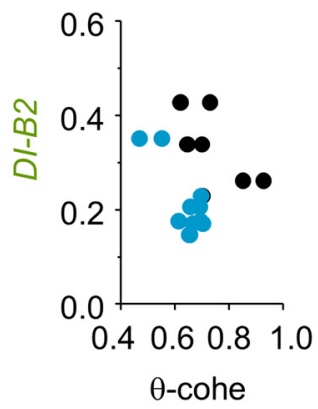

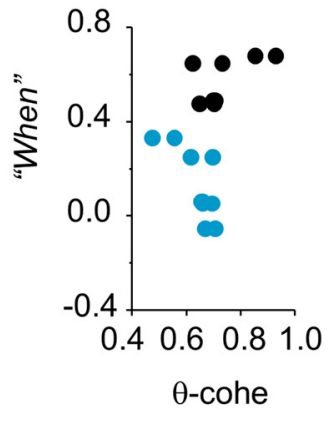

D6

control: $R=0.73 p=0.0375$

epileptic: $n . s$

both: $R=0.64 p=0.0038$

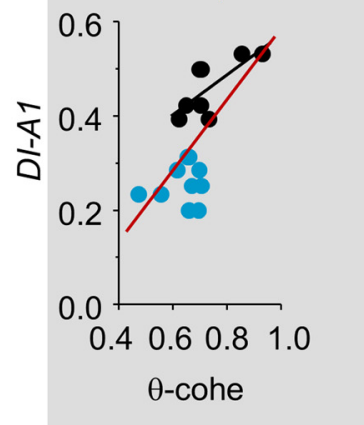

$\mathbf{F}$

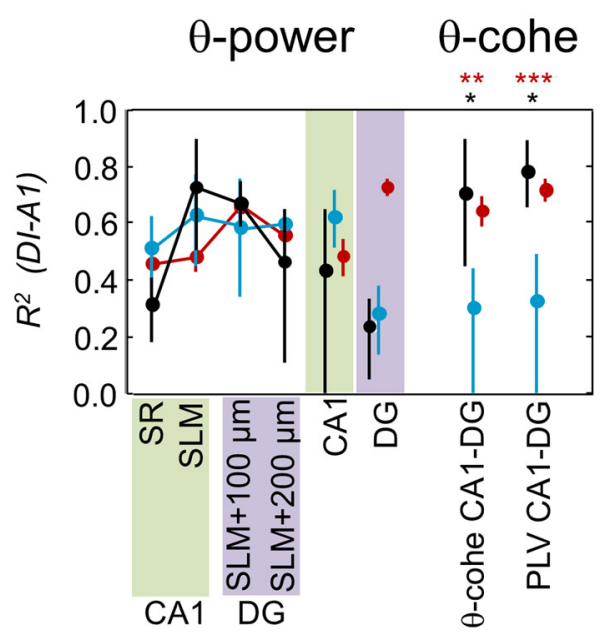

Figure 7. Correlation of electrophysiological and behavioral indices. $A$, Correlation between the SLM theta power and discrimination index where. Note strong correlation for both groups (red) and for the epileptic group alone (blue). $\boldsymbol{A}^{\prime}$, Correlation between SLM theta power and the discrimination index when. Note that clustering of both groups dominates between-group variance, preventing statistical interpretation of linear regression. $\boldsymbol{B}$, We found no correlation between CA1-DG theta coherence and the discrimination index where. $\boldsymbol{B}^{\prime}$, Correlation between CA1-DG theta coherence and the discrimination index when it was dominated by data clustering. C, Correlation between the SLM theta power and the discrimination ratio for object B2 (DI-B2). Note the strong correlation for both groups (red) and for the epileptic group alone (blue). $C^{\prime}$, Correlation between SLM theta power and the discrimination ratio for object A1 (DI-A1). While significant correlation was detected for both groups, neither group alone confirmed the whole population trend. $\boldsymbol{D}$, We found no correlation between CA1-DG theta coherence and the discrimination ratio for object B2 (DI-B2). $D^{\prime}$, Correlation between CA1-DG theta coherence and the discrimination ratio for object A1 (DI-A1). Note the strong correlation for both groups (red) and for the control group alone (black). E, Statistical validation of the regression analysis for DI-B2. Using a leave-one-out procedure, we estimated the mean and SD of the Pearson correlation coefficient $\left(R^{2}\right)$ for each independent variable (theta power and theta coherence at different recording sites). Asterisks denote statistical significance of Pearson correlation for both groups (red) and for the epileptic group alone (blue). $\boldsymbol{F}$, Statistical validation of the regression analysis for DI-A1. Asterisks denote the statistical significance of the Pearson correlation for both groups (red) and for the control group alone (black). ${ }^{*} p<$ $0.05 ; * * 0.01,{ }^{* * *} p<0.001$. 
different processing demands; however, separation of these two attributes of the rhythm is challenging. Our TLE model appears especially suitable to test this hypothesis; individual variability between TLE rats provided examples of animals with relatively preserved oscillatory theta power but strong reduction of its coordination. These animals tend to fail in the temporal aspect of the task but retain memory for the spatial features.

Assisted by multisite recordings, we examined the spatial distribution of theta activity along CA1 and DG strata in TLE rats, and found reduced coordination of theta oscillations between SLM and sites deep into the DG. Since these strata mainly receive direct inputs from the entorhinal cortical layers II and III, which relay different sensory signals into the hippocampus (Witter et al., 2000; Vinogradova, 2001; Bellistri et al., 2013), our data point to specific disruption of cortical inputs to CA1 and DG as a potential substrate for episodic-like memory dysfunction in TLE (Froriep et al., 2012). Genetically targeted interventions suggest that layer III temporoammonic inputs to the hippocampus are involved in some forms of temporal memory, where this treatment does not seem to affect spatial reference memory and the basic properties of place cells (Suh et al., 2011). TLE rats and humans recapitulate to some extent layer III conditional dysfunction in these transgenic mice due to neuronal loss affecting the lateral and medial entorhinal cortex in association with hippocampal sclerosis (Du et al., 1993; Chauvière et al., 2009; Inostroza et al., 2011). In TLE, most entorhinal cell loss is constrained to layer III neurons, giving rise to the temporoammonic pathway that projects to CA1, with layer II neurons giving rise to the perforant pathway to DG being relatively unaffected (Du et al., 1995; see also Chauvière et al., 2009). Possibly, layer III cell loss resulted in abnormal circuit reorganization within the entorhinal cortex, affecting the proper coordination of oscillatory activity in TLE animals (Kumar and Buckmaster, 2006; Froriep et al., 2012). In addition, poor septo-hippocampal coupling (García-Hernández et al., 2010) and changes in intrahippocampal connectivity might also account for impaired theta oscillations in TLE animals.

A deficit in episodic memory is a common cognitive disorder in TLE (Helmstaedter, 2002). Depending on laterality, verbal and nonverbal memories are affected (Gleissner et al., 1998; Dupont et al., 2000; Dige and Wik, 2001), but there is general agreement that time- and context-dependent episodic-like memory is specifically impaired in TLE patients (Helmstaedter, 2002). Whether these cognitive abilities can be fully represented unconsciously by the hippocampus is a matter of debate, but data suggest that humans can learn implicitly complex sequences, suggesting dissociation of at least some processes of episodic memory from the declarative function (Wallenstein et al., 1998; Chun and Phelps, 1999; Rose et al., 2002; Schendan et al., 2003). Using a task previously shown to test for nonverbal correlates of episodic-like memory (Pause et al., 2010), we found that TLE rats exhibit a specific impairment for integrating what-where-when information. Our data exclude effects of interictal discharges, seizures, and other subclinical epileptiform events in task performance, supporting the conclusion that episodic-like memory deficits reflect an intrinsic cognitive dysfunction in TLE.

The strong relation between theta coordination and the temporal component of episodic memory suggests that theta synchrony is a critical mechanism for binding distinct attributes of an event into a single contextual representation. This result, consistent with previous data in humans (Fell et al., 2001; Lega et al., 2012; Fell and Axmacher, 2011), provides experimental support for the identification by Tulving and Markowitsch, 1998 of the temporal dimension as a major attribute of episodic memory. Together with recent genetic and lesion studies (Huerta et al., 2000; Kesner et al., 2005; Nakashiba et al., 2008; Brandon et al., 2011; Suh et al., 2011), our data using a TLE model provide novel insights into the separation of temporal and spatial components of episodic-like memory. Furthermore, we identify different features of oscillatory neuronal activity (i.e., the oscillatory power and coordination) as separate processes potentially underlying this cognitive dissociation.

\section{References}

Addis DR, Moscovitch M, McAndrews MP (2007) Consequences of hippocampal damage across the autobiographical memory network in left temporal lobe epilepsy. Brain 130:2327-2342. CrossRef Medline

Aggleton JP, Pearce JM (2001) Neural systems underlying episodic memory: insights from animal research. Philos Trans R Soc Lond B Biol Sci 356:1467-1482. CrossRef Medline

Aldenkamp AP (1997) Effect of seizures and epileptiform discharges on cognitive function. Epilepsia 38 [Suppl 1]:S52-S55.

Bellistri E, Aguilar J, Brotons-Mas JR, Foffani G, de la Prida LM (2013) Basic properties of somatosensory-evoked responses in the dorsal hippocampus of the rat. J Physiol 591:2667-2686. CrossRef Medline

Benchenane K, Peyrache A, Khamassi M, Tierney PL, Gioanni Y, Battaglia FP, Wiener SI (2010) Coherent theta oscillations and reorganization of spike timing in the hippocampal-prefrontal network upon learning. Neuron 66:921-936. CrossRef Medline

Brandon MP, Bogaard AR, Libby CP, Connerney MA, Gupta K, Hasselmo ME (2011) Reduction of theta rhythm dissociates grid cell spatial periodicity from directional tuning. Science 332:595-599. CrossRef Medline

Buzsáki G (2002) Theta oscillations in the hippocampus. Neuron 33:325340. CrossRef Medline

Chang EH, Huerta PT (2012) Neurophysiological correlates of object recognition in the dorsal subiculum. Front Behav Neurosci 6:46. CrossRef Medline

Chauvière L, Rafrafi N, Thinus-Blanc C, Bartolomei F, Esclapez M, Bernard C (2009) Early deficits in spatial memory and theta rhythm in experimental temporal lobe epilepsy. J Neurosci 29:5402-5410. CrossRef Medline

Chun MM, Phelps EA (1999) Memory deficits for implicit contextual information in amnesic subjects with hippocampal damage. Nat Neurosci 2:844-847. CrossRef Medline

Clayton NS, Dickinson A (1998) Episodic-like memory during cache recovery by scrub jays. Nature 395:272-274. CrossRef Medline

Davachi L (2006) Item, context and relational episodic encoding in humans. Curr Opin Neurobiol 16:693-700. CrossRef Medline

Davis KE, Easton A, Eacott MJ, Gigg J (2013) Episodic-like memory for what-where-which occasion is selectively impaired in the 3xTgAD mouse model of Alzheimer's disease. J Alzheimers Dis 33:681-698. CrossRef Medline

Dere E, Huston JP, De Souza Silva MA (2005) Integrated memory for objects, places, and temporal order: evidence for episodic-like memory in mice. Neurobiol Learn Mem 84:214-221. CrossRef Medline

DeVito LM, Eichenbaum H (2010) Distinct contributions of the hipocampus and medial prefrontal cortex to the "what-where-when" components of episodic-like memory in mice. Behav Brain Res 215:318-325. CrossRef Medline

Dige N, Wik G (2001) A visual learning and memory test for preoperative evaluation of patients with temporal lobe epilepsy. Int J Neurosci 111: 167-174. CrossRef Medline

Du F, Whetsell WO Jr, Abou-Khalil B, Blumenkopf B, Lothman EW, Schwarcz R (1993) Preferential neuronal loss in layer III of the entorhinal cortex in patients with temporal lobe epilepsy. Epilepsy Res 16:223233. CrossRef Medline

Du F, Eid T, Lothman EW, Köhler C, Schwarcz R (1995) Preferential neuronal loss in layer III of the medial entorhinal cortex in rat models of temporal lobe epilepsy. J Neurosci 15:6301-6313. Medline

Dugladze T, Vida I, Tort AB, Gross A, Otahal J, Heinemann U, Kopell NJ, Gloveli T (2007) Impaired hippocampal rhythmogenesis in a mouse model of mesial temporal lobe epilepsy. Proc Natl Acad Sci U S A 104: 17530-17535. CrossRef Medline

Dupont S, Van de Moortele PF, Samson S, Hasboun D, Poline JB, Adam C, Lehéricy S, Le Bihan D, Samson Y, Baulac M (2000) Episodic memory in 
left temporal lobe epilepsy: a functional MRI study. Brain 123:1722-1732. CrossRef Medline

Eacott MJ, Norman G (2004) Integrated memory for objects, place and context in rats: a possible model of episodic-like memory? J Neurosci 24: 1948-1953. CrossRef Medline

Eichenbaum H, Yonelinas AP, Ranganath C (2007) The medial temporal lobe and recognition memory. Annu Rev Neurosci 30:123-152. CrossRef Medline

Ennaceur A, Delacour J (1988) A new one-trial test for neurobiological studies of memory in rats: behavioral data. Behav Brain Res 31:47-59. CrossRef Medline

Fell J, Axmacher N (2011) The role of phase synchronization in memory processes. Nat Rev Neurosci 12:105-118. CrossRef Medline

Fell J, Klaver P, Lehnertz K, Grunwald T, Schaller C, Elger CE, Fernández G (2001) Human memory formation is accompanied by rhinalhippocampal coupling and decoupling. Nat Neurosci 4:1259-1264. CrossRef Medline

Fortin NJ, Agster KL, Eichenbaum HB (2002) Critical role of the hipocampus in memory for sequences of events. Nat Neurosci 5:458-462. CrossRef Medline

Froriep UP, Kumar A, Cosandier-Rimélé D, Häussler U, Kilias A, Haas CA, Egert U (2012) Altered $\theta$ coupling between medial entorhinal cortex and dentate gyrus in temporal lobe epilepsy. Epilepsia 53:1937-1947. CrossRef Medline

García-Hernández A, Bland BH, Facelli JC, Colom LV (2010) Septohippocampal networks in chronic epilepsy. Exp Neurol 222:86-92. CrossRef Medline

Gleissner U, Helmstaedter C, Elger CE (1998) Right hippocampal contribution to visual memory: a presurgical and postsurgical study in patients with temporal lobe epilepsy. J Neurol Neurosurg Psychiatry 65:665-669. CrossRef Medline

Good MA, Hale G, Staal V (2007) Impaired "episodic-like" object memory in adult APPswe transgenic mice. Behav Neurosci 121:443-448. CrossRef Medline

Griffiths D, Dickinson A, Clayton N (1999) Episodic memory: what can animals remember about their past? Trends Cogn Sci 3:74-80. CrossRef Medline

Helmstaedter C (2002) Effects of chronic epilepsy on declarative memory systems. Prog Brain Res 135:439-453. CrossRef Medline

Holmes GL, Lenck-Santini PP (2006) Role of interictal epileptiform abnormalities in cognitive impairment. Epilepsy Behav 8:504-515. CrossRef Medline

Huerta PT, Sun LD, Wilson MA, Tonegawa S (2000) Formation of temporal memory requires NMDA receptors within CA1 pyramidal neurons. Neuron 25:473-480. CrossRef Medline

Hunsaker MR, Kesner RP (2008) Dissociations across the dorsal-ventral axis of CA3 and CA1 for encoding and retrieval of contextual and auditory-cued fear. Neurobiol Learn Mem 89:61-69. CrossRef Medline

Hunsaker MR, Rosenberg JS, Kesner RP (2008) The role of the dentate gyrus, CA3a,b, and CA3c for detecting spatial and environmental novelty. Hippocampus 18:1064-1073. CrossRef Medline

Ibarz JM, Foffani G, Cid E, Inostroza M, Menendez de la Prida L (2010) Emergent dynamics of fast ripples in the epileptic hippocampus. J Neurosci 30:16249-16261. CrossRef Medline

Inostroza M, Binder S, Born J (2013) Sleep-dependency of episodic-like memory consolidation in rats. Behav Brain Res 237:15-22. CrossRef Medline

Inostroza M, Cid E, Brotons-Mas J, Gal B, Aivar P, Uzcategui YG, Sandi C, Menendez de la Prida L (2011) Hippocampal-dependent spatial memory in the water maze is preserved in an experimental model of temporal lobe epilepsy in rats. PLoS One 6:e22372. CrossRef Medline

Inostroza M, Cid E, Menendez de la Prida L, Sandi C (2012) Different emotional disturbances in two experimental models of temporal lobe epilepsy in rats. PLoS One 7:e38959. CrossRef Medline

Jefferys JG, Menendez de la Prida L, Wendling F, Bragin A, Avoli M, Timofeev I, Lopes da Silva FH (2012) Mechanisms of physiological and epileptic HFO generation. Prog Neurobiol 98:250-264. CrossRef Medline

Jones MW, Wilson MA (2005) Theta rhythms coordinate hippocampalprefrontal interactions in a spatial memory task. PLoS Biol 3:e402. CrossRef Medline

Kaplan R, Doeller CF, Barnes GR, Litvak V, Düzel E, Bandettini PA, Burgess N (2012) Movement-related theta rhythm in humans: coordinating self-directed hippocampal learning. PLoS Biol 10:e1001267. CrossRef Medline

Kart-Teke E, De Souza Silva MA, Huston JP, Dere E (2006) Wistar rats show episodic-like memory for unique experiences. Neurobiol Learn Mem 85: 173-182. CrossRef Medline

Kesner RP, Hunsaker MR, Gilbert PE (2005) The role of CA1 in the acquisition of an object-trace-odor paired associate task. Behav Neurosci 119: 781-786. CrossRef Medline

Knierim JJ, Lee I, Hargreaves EL (2006) Hippocampal place cells: parallel input streams, subregional processing, and implications for episodic memory. Hippocampus 16:755-764. CrossRef Medline

Koenig J, Linder AN, Leutgeb JK, Leutgeb S (2011) The spatial periodicity of grid cells is not sustained during reduced theta oscillations. Science 332: 592-595. CrossRef Medline

Kumar SS, Buckmaster PS (2006) Hyperexcitability, interneurons, and loss of GABAergic synapses in entorhinal cortex in a model of temporal lobe epilepsy. J Neurosci 26:4613-4623. CrossRef Medline

Lachaux JP, Rodriguez E, Martinerie J, Varela FJ (1999) Measuring phase synchrony in brain signals. Hum Brain Mapp 8:194-208. CrossRef Medline

Langston RF, Wood ER (2010) Associative recognition and the hippocampus: differential effects of hippocampal lesions on object-place, objectcontext and object-place-context memory. Hippocampus 20:1139-1153. CrossRef Medline

Lega BC, Jacobs J, Kahana M (2012) Human hippocampal theta oscillations and the formation of episodic memories. Hippocampus 22:748-761. CrossRef Medline

Lenck-Santini PP, Rivard B, Muller RU, Poucet B (2005) Study of CA1 place cell activity and exploratory behavior following spatial and nonspatial changes in the environment. Hippocampus 15:356-369. CrossRef Medline

Leutgeb S, Mizumori SJ (1999) Excitotoxic septal lesions result in spatial memory deficits and altered flexibility of hippocampal single-unit representations. J Neurosci 19:6661-6672. Medline

MacDonald CJ, Lepage KQ, Eden UT, Eichenbaum H (2011) Hippocampal "time cells" bridge the gap in memory for discontiguous events. Neuron 71:737-749. CrossRef Medline

Maguire EA, Frith CD (2003) Aging affects the engagement of the hippocampus during autobiographical memory retrieval. Brain 126:15111523. CrossRef Medline

Montgomery SM, Betancur MI, Buzsáki G (2009) Behavior-dependent coordination of multiple theta dipoles in the hippocampus. J Neurosci 29: 1381-1394. CrossRef Medline

Morris RG (2001) Episodic-like memory in animals: psychological criteria, neural mechanisms and the value of episodic-like tasks to investigate animal models of neurodegenerative disease. Philos Trans R Soc Lond B Biol Sci 356:1453-1465. CrossRef Medline

Nakashiba T, Young JZ, McHugh TJ, Buhl DL, Tonegawa S (2008) Transgenic inhibition of synaptic transmission reveals role of CA3 output in hippocampal learning. Science 319:1260-1264. CrossRef Medline

Nakazawa K, Sun LD, Quirk MC, Rondi-Reig L, Wilson MA, Tonegawa S (2003) Hippocampal CA3 NMDA receptors are crucial for memory acquisition of one-time experience. Neuron 38:305-315. CrossRef Medline

Naya Y, Suzuki WA (2011) Integrating what and when across the primate medial temporal lobe. Science 333:773-776. CrossRef Medline

Pause BM, Jungbluth C, Adolph D, Pietrowsky R, Dere E (2010) Induction and measurement of episodic memories in healthy adults. J Neurosci Methods 189:88-96. CrossRef Medline

Place R, Lykken C, Beer Z, Suh J, McHugh TJ, Tonegawa S, Eichenbaum H, Sauvage MM (2012) NMDA signaling in CA1 mediates selectively the spatial component of episodic memory. Learn Mem 19:164-169. CrossRef Medline

Racine RJ (1972) Modification of seizure activity by electrical stimulation: II. Motor seizure. Electroencephalogr Clin Neurophysiol 32:281-294. CrossRef Medline

Roberts WA, Feeney MC, Macpherson K, Petter M, McMillan N, Musolino E (2008) Episodic-like memory in rats: is it based on when or how long ago? Science 320:113-115. CrossRef Medline

Rose M, Haider H, Weiller C, Buchel C (2002) The role of medial temporal lobe structures in implicit learning: an event-related FMRI study Neuron 36:1221-1231. Medline

Sabolek HR, Penley SC, Hinman JR, Bunce JG, Markus EJ, Escabi M, Chrobak 
JJ (2009) Theta and gamma coherence along the septotemporal axis of the hippocampus. J Neurophysiol 101:1192-1200. CrossRef Medline

Schendan HE, Searl MM, Melrose RJ, Stern CE (2003) An FMRI study of the role of the medial temporal lobe in implicit and explicit sequence learning. Neuron 37:1013-1025. CrossRef Medline

Sigurdsson T, Stark KL, Karayiorgou M, Gogos JA, Gordon JA (2010) Impaired hippocampal-prefrontal synchrony in a genetic mouse model of schizophrenia. Nature 464:763-767. CrossRef Medline

Suárez LM, Cid E, Gal B, Inostroza M, Brotons-Mas JR, Gómez-Domínguez D, de la Prida LM, Solís JM (2012) Systemic injection of kainic acid differently affects LTP magnitude depending on its epileptogenic efficiency. PLoS One 7:e48128. CrossRef Medline

Suh J, Rivest AJ, Nakashiba T, Tominaga T, Tonegawa S (2011) Entorhinal cortex layer III input to the hippocampus is crucial for temporal association memory. Science 334:1415-1420. CrossRef Medline

Thomson DJ (1982) Spectrum estimation and harmonic analysis. Proc IEEE 70:1055-1096. CrossRef

Tort AB, Komorowski R, Kopell N, Eichenbaum H (2011) A mechanism for the formation of hippocampal neuronal firing patterns that represent what happens where. Learn Mem 18:718-727. CrossRef Medline
Tort AB, Komorowski RW, Manns JR, Kopell NJ, Eichenbaum H (2009) Theta-gamma coupling increases during the learning of item-context associations. Proc Natl Acad Sci U S A 106:20942-20947. CrossRef Medline

Tsien JZ, Huerta PT, Tonegawa S (1996) The essential role of hippocampal CA1 NMDA receptor-dependent synaptic plasticity in spatial memory. Cell 87:1327-1338. CrossRef Medline

Tulving E, Markowitsch HJ (1998) Episodic and declarative memory: role of the hippocampus. Hippocampus 8:198-204. Medline

Vinogradova OS (2001) Hippocampus as comparator: role of the two input and two output systems of the hippocampus in selection and registration of information. Hippocampus 11:578-598. CrossRef Medline

Wallenstein GV, Eichenbaum H, Hasselmo ME (1998) The hippocampus as an associator of discontiguous events. Trends Neurosci 21:317-323. CrossRef Medline

Witter MP, Naber PA, van Haeften T, Machielsen WC, Rombouts SA, Barkhof F, Scheltens P, Lopes da Silva FH (2000) Cortico-hippocampal communication by way of parallel parahippocampal-subicular pathways. Hippocampus 10:398-410. CrossRef Medline 